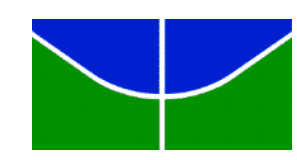

UNIVERSIDADE DE BRASÍLIA INSTITUTO DE CIÊNCIAS BIOLÓGICAS PROGRAMA DE PÓS-GRADUAÇÃO EM ECOLOGIA

CALliphORIDAE E SARCOPHAGIDAE (DIPTERA) INDICADORES DE ESTÁGIOS DE DECOMPOSIÇÃO E SUCESSÃO ECOLÓGICA EM CARCAÇAS DE PORCOS DE PEQUENA BIOMASSA

Suéle Fatima Santolin

Brasília - DF

Abril de 2015 


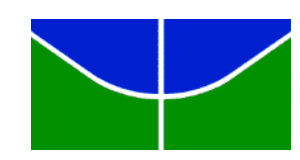

UNIVERSIDADE DE BRASÍLIA INSTITUTO DE CIÊNCIAS BIOLÓGICAS PROGRAMA DE PÓS-GRADUAÇÃO EM ECOLOGIA

\section{CALliphoridae e SARCOPHAGIDAE (DIPTERA) INDICADORES DE ESTÁGIOS DE DECOMPOSIÇÃO E SUCESSÃO ECOLÓGICA EM CARCAÇAS DE PORCOS DE PEQUENA BIOMASSA}

Suéle Fatima Santolin

Orientador: Prof. Dr. José Roberto Pujol Luz

Dissertação de mestrado apresentada ao Programa de Pós-graduação em Ecologia da Universidade de Brasília como requisito para obtenção do título de Mestre em Ecologia

Brasília - DF

Abril de 2015 


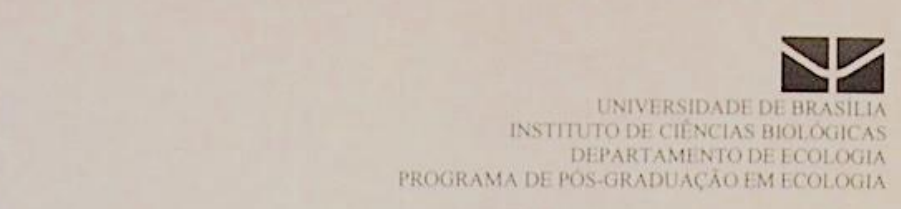

Dissertação de Mestrado

\section{SUÉLE FATIMA SANTOLIN}

Titulo:

"CALLIPHORIDAE E SARCOPHAGIDAE (DIPTERA) INDICADORES DE ESTÁGIOS DE DECOMPOSIÇÃO E SUCESSÃO ECOLÓGICA EM

CARCAÇAS DE PORCOS DE PEQUENA BIOMASSA"

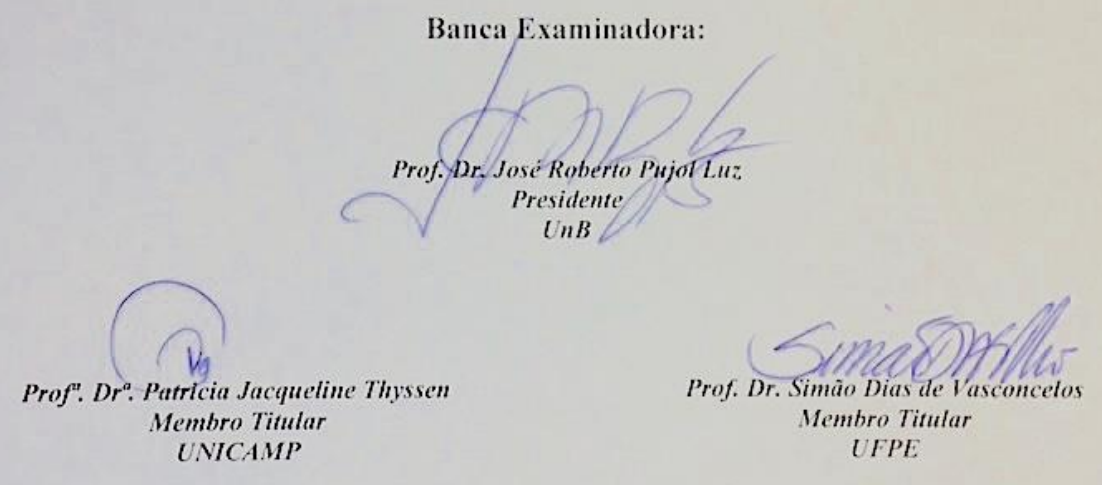

Prof". Dr". Ivone Rezende Diniz

Suplente

UnB

Brasilia, 24 de abril de 2015 . 


\section{Agradecimentos}

Muitas pessoas foram decisivas para a realização desse trabalho. Deixo aqui meus sinceros agradecimentos.

À minha família, pela compreensão e apoio em todos os momentos desta caminhada.

Ao Alan, que esteve ao meu lado desde o início dessa caminhada e sempre me encorajou a seguir em frente. Seu amor, carinho, atenção e apoio foram essenciais para a realização desse trabalho. Além de tudo, me auxiliou nos trabalhos de campo e nas análises dos dados.

Ao Professor Dr. José Roberto Pujol Luz, que mesmo sem me conhecer depositou sua confiança em mim e no meu trabalho. Sou grata pela excelente orientação, valiosas conversas e conselhos, e muitas oportunidades de aprendizagem que tive desde o início do mestrado.

Ao Professor Dr. Luiz U. Hepp pelo auxílio no delineamento experimental e na análise dos dados.

Aos Professores, Dra. Cristiane V. A. Pujol Luz, Dr. Antônio Aguiar, Dr. Kleber Mise, Dr. Carla Bicho e ao doutorando Thiago Frizo pelo auxílio na identificação dos insetos.

As colegas Ana Maria, Ana Carolina, Érica, Karine e Meiriane pela ajuda na identificação de alguns insetos.

Aos colegas da Pós-graduação do Laboratório de Entomologia Forense (Karine, Érica, Ana, Maroca, Welinton e Marcos) pelos ensinamentos. 
Aos bolsistas e estagiários do Laboratório de Entomologia Forense (Samuel, Lucas, Jheniffer, Lara, Taís, Bárbara, Isabela e Matheus) pelo auxílio em campo e na confecção das armadilhas em laboratório.

Aos meus colegas de mestrado Vinicius e Laís pelas risadas e conversas. Além é claro do auxílio nas coletas de campo.

Ao técnico de campo da Ecologia Sr. Mardônio e ao motorista Sr. Vandélio pelo auxílio em campo.

Aos meus amigos de mestrado e doutorado (Laís, Vinícius, Thalita, Pedro, Juliana e Romina) pelas conversas, conselhos e risadas. Foi muito bom conhecer e conviver com vocês.

Ao Carlos e Raquel acima de tudo pela amizade, mas também pelo suporte durante a minha estadia em Brasília.

Ao Programa de Pós-graduação em Ecologia da UnB e a todos os professores que tive durante o mestrado, os quais contribuíram muito para minha formação profissional.

Ao CNPq pela concessão da bolsa de estudos. 


\section{LISTA DE FIGURAS}

FIGURA 1. Caracterização das fitofisionomias de mata de galeria (A) e do cerrado sensu stricto $(\mathrm{B})$

FIGURA 2. Localização das três áreas delimitadas para a fitofisionomia do cerrado sensu stricto (pontos pretos) e de mata de galeria (estrela branca). Cada ponto indica o local onde as carcaças foram instaladas.

FIGURA 3. Armadilha utilizada para coleta dos dípteros adultos .23

FIGURA 4. Regressão linear entre a temperatura do ar e a duração do processo de decomposição (em dias) nas fitofisionomias de mata de galeria e cerrado sensu stricto

FIGURA 5. Estágios de decomposição fresco (A), decomposição ativa (B), decomposição avançada (C) e seco (D) observados nas carcaças expostas na mata de galeria. 30

FIGURA 6. Estágios de decomposição fresco (A), decomposição ativa (B), decomposição avançada (C) e seco (D) observados nas carcaças expostas no cerrado sensu stricto

FIGURA 7. Espécies de dípteros pertencentes à família Sarcophagidae (letras A à H) registradas ao longo do processo de decomposição. As letras indicam as espécies: A (Peckia anguilla), B (Peckia collusor), C (Peckia ingens), D (Peckia intermutans), E (Peckia pexata), F (Peckia trivittata), G (Oxysarcodexia fluminensis), $\mathrm{H}$ (Oxysarcodexia thornax)

FIGURA 8. Espécies de dípteros pertencentes à família Calliphoridae (letras A à H) registradas ao longo do processo de decomposição. As letras indicam as espécies: A 
(Chrysomya albiceps), B (Chrysomya megacephala), C (Chloroprocta idioidea), D (Lucilia eximia), E (Hemilucilia segmentaria), F (Hemilucilia semidiaphana), G (Cochliomyia macellaria) e H (Mesembrinella bicolor).

FIGURA 9. Análise de agrupamento da composição de dípteros necrófagos em carcaças expostas na mata de galeria (A) e no cerrado sensu stricto (B) considerando os estágios de decomposição (em dias). Os estágios de decomposição são indicados por: fresco (F), decomposição ativa (AT), decomposição avançada (AV) e, seco (S). Os números indicam o dia do experimento. Os números em romanos (I, II, III e IV) indicam os grupos formados para cada fitofisionomia 49 


\section{LISTA DE TABELAS}

TABELA 1. Frequência relativa de insetos ao longo dos estágios de decomposição ( $F=$ fresco, $\mathrm{AT}=$ decomposição ativa, $\mathrm{AV}=$ decomposição avançada e, $\mathrm{S}=$ seco) em carcaças expostas na mata de galeria. A frequência relativa se baseia no número de ocorrência de cada táxon nas carcaças durante os dias do experimento. As barras contínuas $(\longmapsto$ ) indicam a variação mínima e máxima na duração dos estágios de

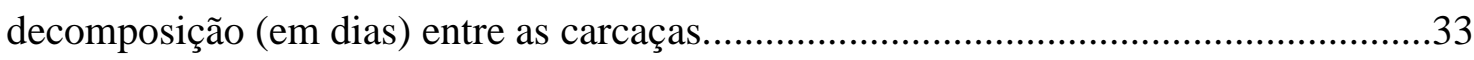

TABELA 2. Frequência relativa de insetos ao longo dos estágios de decomposição ( $\mathrm{F}=$ fresco, $\mathrm{AT}=$ decomposição ativa, $\mathrm{AV}=$ decomposição avançada e, $\mathrm{S}=$ seco) em carcaças expostas no cerrado sensu stricto. A frequência relativa se baseia no número de ocorrência de cada táxon nas carcaças durante os dias do experimento. As barras contínuas $(\longmapsto)$ indicam a variação mínima e máxima na duração dos estágios de

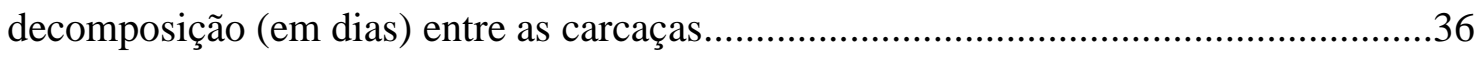

TABELA 3. Espécies de dípteros indicadoras dos estágios de decomposição nas fitofisionomias de mata de galeria (MG) e no cerrado sensu stricto (SS). VI indica o valor de indicação das espécies.

TABELA 4. Matriz de ocorrência (presença/ausência) de dípteros necrófagos pertencentes às famílias Calliphoridae e Sarcophagidae associada às carcaças expostas no cerrado sensu stricto. .44

TABELA 5. Matriz de ocorrência (presença/ausência) de dípteros necrófagos pertencentes às famílias Calliphoridae e Sarcophagidae associada às carcaças expostas na mata de galeria......

TABELA 6. Frequência relativa das espécies de dípteros necrófagos pertencentes às famílias Calliphoridae e Sarcophagidae ao longo dos estágios de decomposição ( $\mathrm{F}=$ 
fresco, $\mathrm{AT}=$ decomposição ativa, $\mathrm{AV}=$ decomposição avançada e, $\mathrm{S}=$ seco) em carcaças expostas no cerrado sensu stricto. A frequência relativa se baseia no número de ocorrência de cada espécie nas carcaças durante os dias do experimento. As barras contínuas $(\longmapsto)$ indicam a variação mínima e máxima na duração dos estágios de

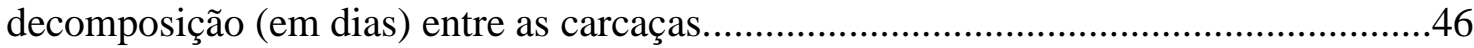

TABELA 7. Frequência relativa das espécies de dípteros necrófagos pertencentes às famílias Calliphoridae e Sarcophagidae ao longo dos estágios de decomposição (F = fresco, $\mathrm{AT}=$ decomposição ativa, $\mathrm{AV}=$ decomposição avançada e, $\mathrm{S}=$ seco) em carcaças expostas na mata de galeria. A frequência relativa se baseia no número de ocorrência de cada espécie nas carcaças durante os dias do experimento. As barras contínuas $(\longmapsto$ ) indicam a variação mínima e máxima na duração dos estágios de decomposição (em dias) entre as carcaças 


\section{Sumário}

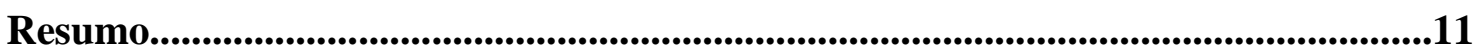

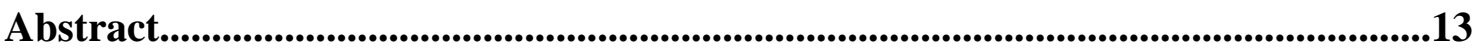

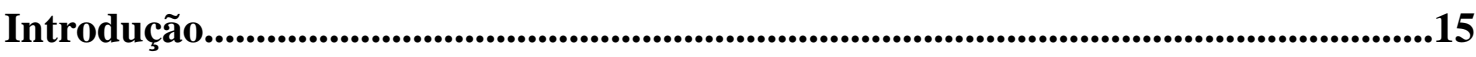

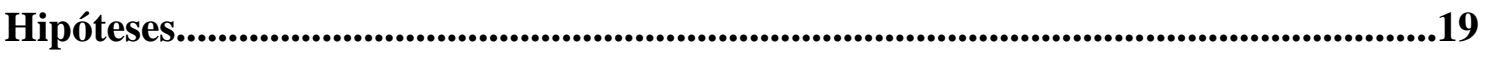

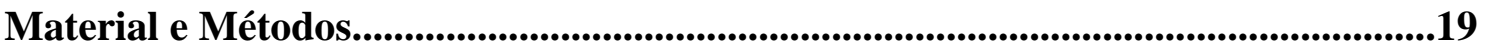

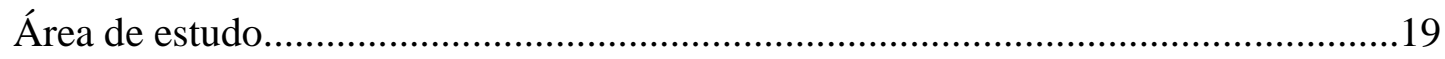

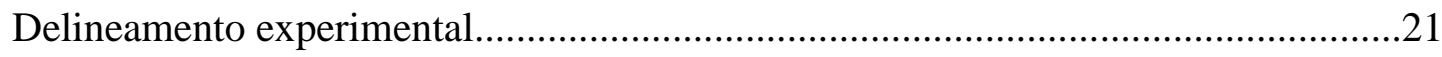

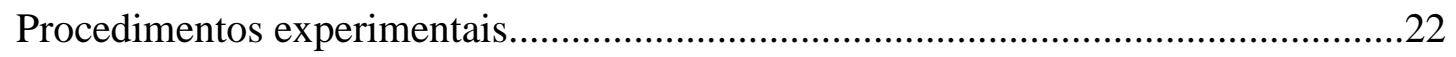

Estágios de decomposição e comunidade de artrópodos visitantes.............................25

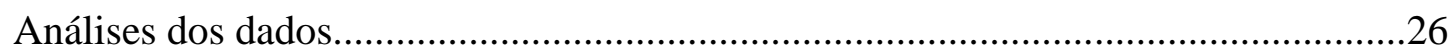

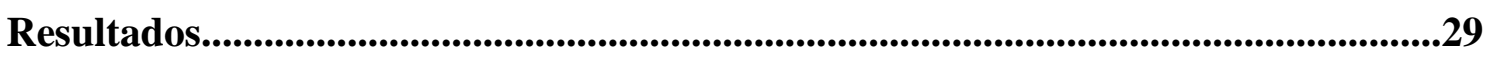

Tempo e estágios de decomposição das carcaças....................................................29

Composição e sucessão de dípteros necrófagos nas carcaças......................................31

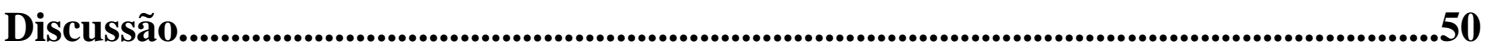

Tempo e estágios de decomposição das carcaças......................................................50

Composição e sucessão de dípteros necrófagos nas carcaças....................................51

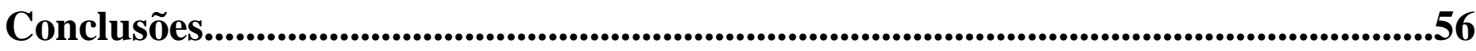

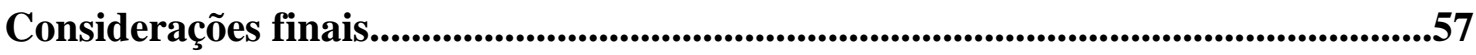

Referências Bibliográficas.........................................................................................................58 


\section{Resumo}

A identificação do processo de sucessão de dípteros necrófagos em carcaças e dos fatores que influenciam o processo de decomposição das carcaças são importantes para entender a dinâmica de recursos efêmeros. Neste estudo, foi avaliado se há e como ocorre a sucessão de dípteros necrófagos e a duração do processo de decomposição em carcaças de pequena biomassa em duas fitofisionomias do Cerrado que apresentam condições microclimáticas contrastantes. Cada fitofisionomia foi composta por três áreas distanciadas cerca de $1 \mathrm{~km}$ entre si. Em cada área foram colocadas duas carcaças, perfazendo um total de 12 carcaças. A coleta de imaturos, dos dípteros adultos e o monitoramento das carcaças foram realizados diariamente (9-14h). As variáveis microclimáticas tais como temperatura e umidade do ambiente também foram mensuradas diariamente nas proximidades de cada carcaça. A decomposição das carcaças foi mais rápida no cerrado sensu stricto do que na mata de galeria. Além disso, observamos quatro estágios de decomposição, sendo que apenas as fases fresca e de decomposição ativa apresentaram diferença significativas entre as fitofisionomias. Ambos os estágios de decomposição foram mais prolongados na mata de galeria. Estes resultados podem ser atribuídos às variações nas condições microclimáticas (p.ex., temperatura e umidade) de cada local, decorrentes da estrutura da vegetação. Diferenças na composição de dípteros necrófagos entre as fitofisionomias foram observadas, uma vez que as diferenças microclimáticas oferecem condições propícias para determinadas espécies em cada ambiente. Além disso, observamos espécies de dípteros indicadoras dos estágios de decomposição fresco na mata de galeria e de decomposição avançada e seco no cerrado sensu stricto. Observamos sucessão de dípteros necrófagos nas duas fitofisionomias, sendo possível observar uma sequência semelhante de espécies nos dois ambientes. O processo de sucessão de dípteros apresentou-se como um contínuo de 
mudanças graduais ao longo do processo de decomposição, visto que não há uma composição da fauna distinta para cada fase. Uma implicação importante deste estudo é de que ao avaliar a sucessão de insetos em carcaças a descrição dos estágios de decomposição deve ser utilizada com cautela, visto que a comunidade visitante não responde a estas características físicas descritas na literatura.

Palavras-chave: decomposição de carcaças, dípteros necrófagos, cerrado sensu stricto, mata de galeria. 


\section{Abstract}

The identification of insect succession pattern in carcasses and the factors that factors affecting the decomposition process of the carcasses is important in the dynamics of ephemeral resources. This study evaluated if, and how there is a succession of necrophagous flies and the time of the decomposition process in small biomass carcasses in two Cerrado vegetation types that present contrasting microclimate conditions. Each vegetation type was composed of three areas spaced about $1 \mathrm{~km}$ apart. In each area we were placed two carcasses, for a total of 12 carcasses. The collection of immature, adult flies and monitoring of carcasses were performed daily (9-14h). The microclimate variables such as temperature and humidity of the environment were also measured daily in the vicinity of each carcass. The decomposition of the carcasses was faster in cerrado sensu stricto than in gallery forest. We observed four stages of decomposition, and only the fresh and active decomposition stages, showed significative differences in the vegetation types. Both stages of decomposition were longer in the gallery forest. These results can be attributed to changes in microclimate conditions (e.g. temperature and humidity) of each local stemming from vegetation structure. Differences in the composition of necrophagous Diptera were observed among the three types of vegetation, since the microclimatic differences offer favorable conditions for certain species in each environment. Moreover, we observed some species of flies that indicate the fresh decomposition stages in the gallery forest, and also in the advanced dry decomposition in the cerrado. We observe succession flies scavengers in both vegetation types and are recording a similar sequence of species in both environments. The succession process was presented as a continuum of gradual changes throughout the decomposition process, since there is not a composition of distinct fauna for each phase. An important implication of this study is that when 
evaluating the succession of insects on carcasses describing the stages of decomposition should be used with caution, since the visitor community does not respond to these physical characteristics described in the literature.

Keywords: decomposition of carcasses, diptera necrophagous, cerrado sensu stricto, gallery forest. 


\section{Introdução}

O conceito de sucessão ecológica é amplamente conhecido, mas sua definição é ainda incerta. O termo sucessão ecológica é utilizado para descrever a substituição de espécies que compõem uma comunidade em diferentes escalas, temporal e espacial (Miranda 2009). Em recursos efêmeros, tais como carcaças de animais em decomposição, o processo de sucessão também pode ser observado, sendo este definido como a colonização por vários organismos e a posterior substituição de espécies ao longo do processo de decomposição (Catts e Goff 1992). O conceito de sucessão proposto para comunidade de plantas difere da sucessão em carcaças, visto que nesta última não há formação de um estado clímax da comunidade (Schoenly e Reid 1987). Isto é decorrente da curta duração deste recurso no ambiente, impedindo o estabelecimento de uma comunidade clímax (Schoenly e Reid 1987). Todavia, apesar da baixa disponibilidade temporal deste recurso no ambiente, carcaças podem ser consideradas como sistemas discretos, onde identificam-se padrões temporais de distribuição de insetos ao longo do tempo (Schoenly e Reid 1987).

Padrões de distribuição são determinados pelas mudanças nas condições físicas e químicas da carcaça, já que esta sofre alterações ao longo do processo de decomposição, onde cada etapa torna-se atrativa para diferentes espécies visitantes (Bornemissza 1957; Carvalho e Linhares 2001). Tais padrões de distribuição da fauna em carcaças podem então ser considerados como um contínuo de mudanças graduais na composição da fauna (Schoenly e Reid 1987; Boulton e Lake 1988; Moura et al. 2005) ou com limites discretos, onde há presença de uma fauna distinta para cada estágio de decomposição (Payne 1965; Voss et al. 2009). 
Múltiplos trabalhos envolvendo sucessão de insetos em recursos efêmeros foram desenvolvidos em diferentes regiões geográficas (e.g. Bornemissza 1957; Payne 1965; Monteiro-Filho e Penereiro 1987; Tantawi et al. 1996; Grassberger e Frank 2004; Sharanowski et al. 2008; Matuszewski et al. 2011; Voss et al. 2011; Aballay et al. 2012), entretanto é necessário que cada região forneça informações sobre os padrões de sucessão da fauna de insetos em carcaças, já que estes variam de forma significativa entre diferentes locais devido às condições microclimáticas existentes (Smith 1986; Mann et al. 1990; Oliveira-Costa e Mello-Patiu 2004).

A variabilidade nas taxas de decomposição e nos padrões de sucessão são atribuídas a uma série de variáveis, entre estas o tamanho da carcaça (e.g. Sharanowski et al. 2008; Simmons et al. 2010; Sutherland et al. 2013). A maioria dos estudos utilizaram carcaças de média ou grande biomassa (maior que $15 \mathrm{~kg}$ ) como sistemas modelos (Sharanowski et al. 2008; Simmons et al. 2010; Matuszewski et al. 2011, 2014). Entretanto, carcaças com menor biomassa decompõem quase três vezes mais rápido do que carcaças grandes (Catts e Goff 1992; Sutherland et al. 2013), devido à menor massa corporal, bem como às diferenças na composição óssea das carcaças (Archer 2004). Isso evidencia que os padrões de sucessão e as taxas de decomposição de carcaças de pequena biomassa provavelmente são variáveis e devem ser também alvo de estudos devido à menor biomassa disponível para colonização e consumo.

Outros fatores também podem interferir na taxa de decomposição e na sucessão da fauna em carcaças como a temperatura (Sutherland et al. 2013), umidade (Archer 2004), precipitação (Archer 2004), luminosidade (Matuszewski et al. 2008), período do ano (Sharanowski et al. 2008; Matuszewski et al. 2010), tipo de habitat (Sharanowski et al. 2008), e o acesso dos insetos às carcaças (Simmons et al. 2010; Pechal et al. 2014). Com isso, é esperado que carcaças expostas a diferentes condições microclimáticas e 
biológicas apresentem diferenças nas taxas de decomposição e na composição de espécies necrófagas (Smith 1986; Pechal et al. 2014). Isto é relevante considerando as condições contrastantes observadas em muitos ecossistemas naturais, por exemplo, nas fitofisionomias do bioma Cerrado, onde os ecossistemas variam de formações savânicas (e.g. cerrado sensu stricto) a densas Matas de Galeria.

Os insetos são o maior grupo taxonômico em termos de riqueza de espécies, sendo encontrados em diversos habitats (Rafael et al. 2012). Dentre os habitats comuns aos insetos, carcaças em decomposição são locais e recursos essenciais ao desenvolvimento desses organismos (Anderson et al. 2002). Os dípteros são os primeiros animais a reconhecer a carcaça como um recurso poucos minutos após a morte. Isso se deve ao fato desses insetos possuírem órgãos sensoriais altamente especializados para detecção de odores (Campobasso et al. 2001) o que os torna aptos a utilizar a carcaça como sítio de cópula, oviposição ou larviposição, ou como fonte proteica (Oliveira-Costa 2008). Além disso, as famílias de dípteros Calliphoridae e Sarcophagidae são considerados colonizadores iniciais de carcaças e responsáveis pela redução da maior parte da biomassa destes recursos (Bharty e Singh 2003).

Insetos da família Calliphoridae, popularmente conhecidos como moscas varejeiras, apresentam coloração do corpo verde ou azul metálico (Scudder e Cannings 2006). Esta família está dividida em oito subfamílias: Chrysomyinae, Toxotarsinae, Calliphorinae, Luciliinae, Mesembrinellinae, Polleniinae, Melanomyinae e Rhiniinae (Rognes 1997). Destas subfamílias apenas as três últimas não ocorrem no Brasil. Em todo mundo esta família é composta por mais de 1.000 espécies e 150 gêneros (Scudder e Cannings 2006). Para o Brasil, são registradas 37 espécies pertencentes à 15 gêneros (Kosmann et al. 2013). 
Representantes da família Sarcophagidae não possuem um nome popular conhecido no Brasil, mas representantes desta família apresentam três faixas transversais escuras no tórax e abdômen com padrão xadrez (Scudder e Cannings 2006). A família é dividida em três subfamílias, Miltogrammatinae, Paramacronychiinae e Sarcophaginae, as quais esta última é a que contém maior número de espécies sendo muitas dessas de importância forense (Pape 1996). No mundo são conhecidas 2.600 espécies, enquanto que no Brasil são conhecidas aproximadamente 350 espécies (Pape 1996). As espécies necrófagas pertencentes a estas famílias desempenham importante papel ecológico, pois auxiliam na decomposição da matéria orgânica e na ciclagem de nutrientes. Assim, considerando as fases de decomposição de uma carcaça animal e a composição de espécies visitantes, é possível estimar uma sequência de colonização dos insetos nas carcaças. De acordo com Bornemissza (1957) e Payne (1972) alguns gêneros das famílias Calliphoridae (Lucilia, Chrysomya, Cochliomyia e Calliphora) e Sarcophagidae são abundantes durante o processo de decomposição, podendo ocorrer alterações sucessionais entre estes.

Diante disso, o objetivo deste estudo foi avaliar se há, e como ocorre, a sucessão da fauna de dípteros necrófagos e se a duração do processo de decomposição em carcaças de pequena biomassa difere entre duas fitofisionomias com condições microclimáticas contrastantes a fim de responder às seguintes questões: (i) a duração do processo de decomposição (em dias) e a duração de cada estágio de decomposição diferem entre as duas fitofisionomias? (ii) a composição de espécies de dípteros necrófagos difere entre as duas fitofisionomias com condições microclimáticas contrastantes? (iii) é possível observar espécies indicadoras de determinados estágios de decomposição nas duas fitofisionomias? (iv) há sucessão de dípteros necrófagos em carcaças de pequena biomassa nas duas fitofisionomias? e, (v) caso houver sucessão de 
dípteros necrófagos, o processo apresenta limites discretos ou é um contínuo de mudanças graduais na composição de espécies?

\section{Hipóteses}

(i) A decomposição das carcaças é mais rápida e a duração dos estágios de decomposição é menor no cerrado sensu stricto do que na mata de galeria, devido à maior temperatura e exposição.

(ii) A composição de espécies de dípteros necrófagos nas carcaças do cerrado sensu stricto difere da de mata de galeria, devido às diferenças nas condições microclimáticas de cada ambiente.

(iii) Há presença de espécies indicadoras dos estágios de decomposição para ambas as fitofisionomias, devido que cada estágio apresenta mudanças nas condições das carcaças tornando-se atrativa para diferentes espécies ao longo do processo de decomposição.

(iv) Há sucessão de dípteros necrófagos durante o processo de decomposição de carcaças de pequena biomassa nas duas fitofisionomias, devido às diferenças nas características físicas e químicas da carcaça que a tornam-se atrativa para diferentes espécies ao longo do processo de decomposição.

\section{Material e Métodos}

Área de estudo

O estudo foi realizado na Estação Ecológica do Jardim Botânico de Brasília $\left(15^{\circ} 50^{\prime}-15^{\circ} 55^{\prime} \mathrm{S}, 47^{\circ} 49^{\prime}-47^{\circ} 55^{\prime} \mathrm{W}\right)$. Esta possui uma área total de 5.000 ha e está 
inserida juntamente com a Fazenda Água Limpa (FAL) e a Reserva Ecológica do Instituto Brasileiro de Geografia e Estatística (RECOR) na Área de Proteção Ambiental (APA) das Bacias do Gama e Cabeça de Veado (Lacerda et al. 2007).

A área de estudo está inserida no bioma Cerrado que representa cerca de $23 \%$ do território brasileiro e apresenta elevada taxa de biodiversidade e presença de ecossistemas distintos (Ibama, 2001). O clima da região é classificado como Aw Köppen (tropical chuvoso), com ocorrência de duas estações bem definidas, uma seca (abril a setembro) e outra chuvosa (outubro a março; Ribeiro e Walter 2008). A precipitação média anual é de $1.500 \mathrm{~mm}$ com temperaturas variando de 22 a $27{ }^{\circ} \mathrm{C}$ (Eiten 1972).

O experimento foi realizado em duas fitofisionomias do Cerrado, sendo estas mata de galeria e cerrado sensu stricto (Figura 1). A formação florestal do cerrado sensu stricto é a forma mais extensa e ocupa cerca de $65 \%$ da área geográfica do bioma. Este tipo de formação vegetal ocorre em solos mais rasos e caracteriza-se pela presença de árvores baixas, inclinadas, retorcidas e com indicativos de queimada (Ribeiro e Walter 2008). Enquanto a fisionomia de mata de galeria ocupa cerca de 5\% da área do Cerrado, esta ocorre em solos mais profundos e distribui-se ao longo de rios e córregos de pequeno porte, formando corredores fechados sobre os cursos de água (Ribeiro e Walter 2008). 

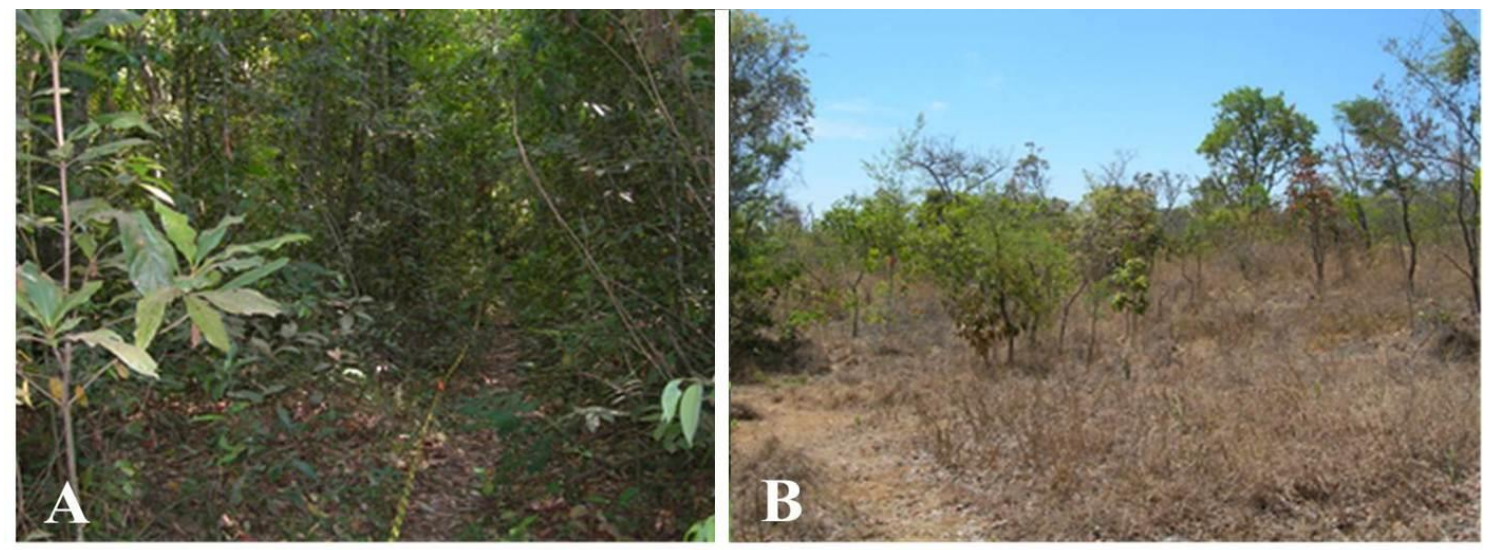

Figura 1. Caracterização das fitofisionomias de mata de galeria (A) e do cerrado sensu stricto (B).

\section{Delineamento experimental}

Cada fitofisionomia foi composta por três áreas distanciadas aproximadamente um quilômetro, a fim de garantir a independência entre as carcaças em decomposição (Figura 2). Em cada área foram colocadas duas carcaças pequenas de porcos domésticos (Sus scrofa, Linnaeus 1758), com massa corporal variando de $0,9 \mathrm{~kg}$ a 2,2 kg, com um total de 12 carcaças (Figura 2). Anteriormente à instalação do experimento no campo, todas as carcaças foram pesadas, a fim de padronizar a massa corporal das carcaças utilizadas. Entretanto, devido às diferenças na massa corporal existente entre as carcaças adquiridas, estas foram distribuídas de maneira aleatória entre os ambientes a fim de diminuir esta influência e evitar resultados tendenciosos. Além disso, foi realizado um teste estatístico e observamos que não há diferença na biomassa inicial das carcaças entre as duas fitofisionomias $\left(t_{10}=0.465, P=0,652\right)$. As carcaças utilizadas foram de porcos natimortos doados por uma propriedade rural de Brasília-DF. Anteriormente a instalação do experimento a campo, as carcaças foram acondicionadas em caixas de isopor a fim de evitar a contaminação por larvas de dípteros.

A distância entre as carcaças de porcos expostas dentro da mesma fitofisionomia foi de $50 \mathrm{~m}$, e entre as duas fitofisionomias foram de $150 \mathrm{~m}$ (Figura 2). Neste trabalho 
optamos pela utilização de carcaças de porcos devido a sua semelhança com humanos, quanto a sua anatomia interna, fisiologia e quantidade de pelos (Campobasso et al. 2001). As condições microclimáticas diárias (temperatura e umidade relativa do ar) de cada fitofisionomia foram mensuradas nas proximidades de cada carcaça com o auxílio de um termo-higrômetro (Temperatur-Luftfeuchtigkeits-Sender ${ }^{\circledR}$ ).

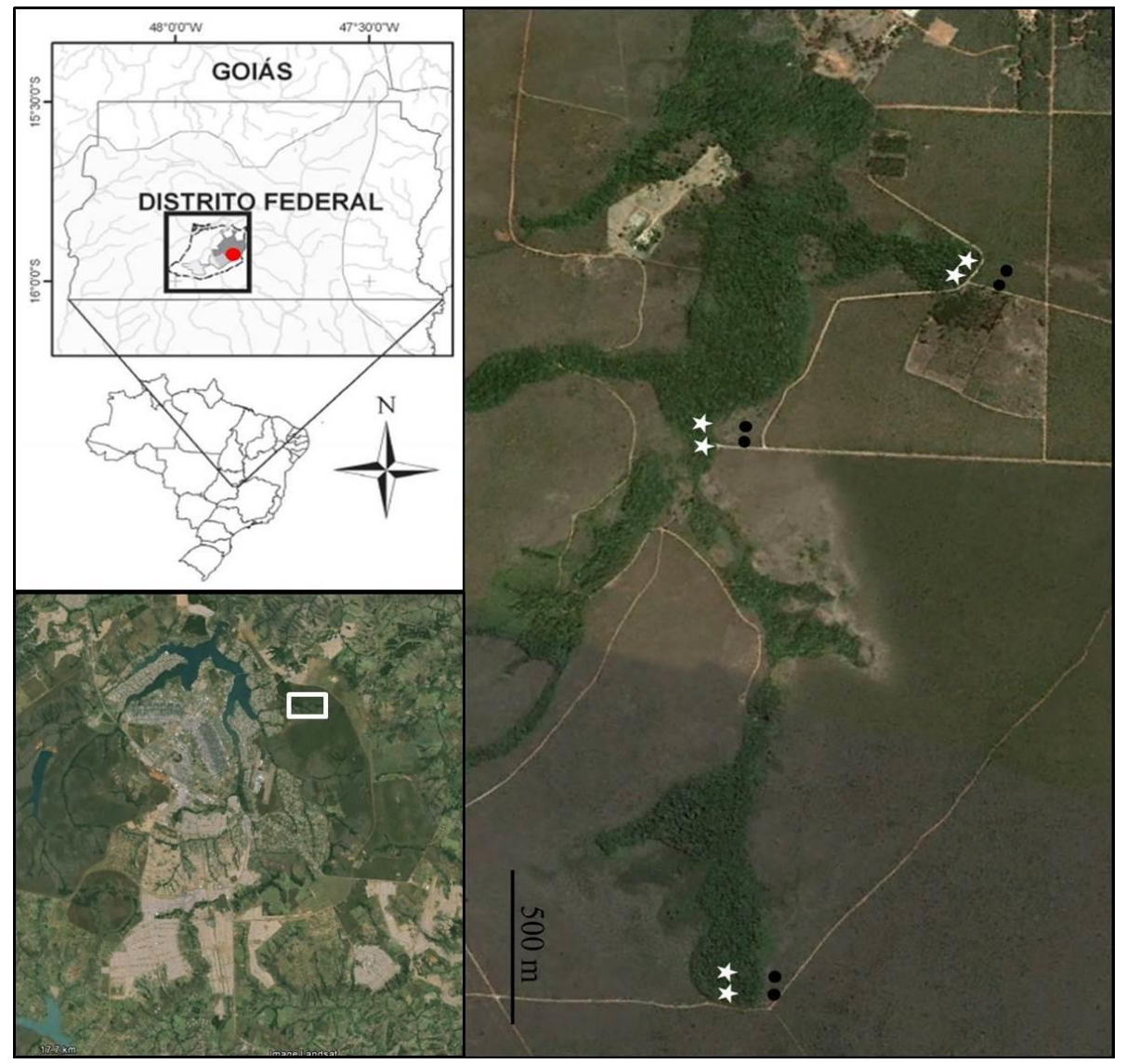

Figura 2. Localização das três áreas delimitadas para a fitofisionomia do cerrado sensu stricto (pontos pretos) e de mata de galeria (estrela branca). Cada ponto indica o local onde as carcaças foram instaladas.

\section{Procedimentos experimentais}

O experimento foi realizado durante a estação seca (setembro/2014). A armadilha utilizada foi modificada do modelo conhecido como cone trap (Bioquip 2012). Assim, em cada uma das fitofisionomias, as carcaças foram protegidas por tela 
(malha de $1 \mathrm{~cm}$ ), sendo fixadas no chão através de vergalhões de aço a fim de evitar que animais de grande porte interferissem no experimento. Abaixo de cada carcaça foi colocada uma bandeja com vermiculita para coleta de imaturos, e acima, bancos de plásticos contendo no seu ápice uma garrafa pet para coleta dos insetos adultos. No entorno de cada banco foi colocado um tecido de algodão escuro. Juntamente a este tecido escuro foi feito um cone de papel craft para direcionar os insetos para dentro da garrafa (Figura 3).

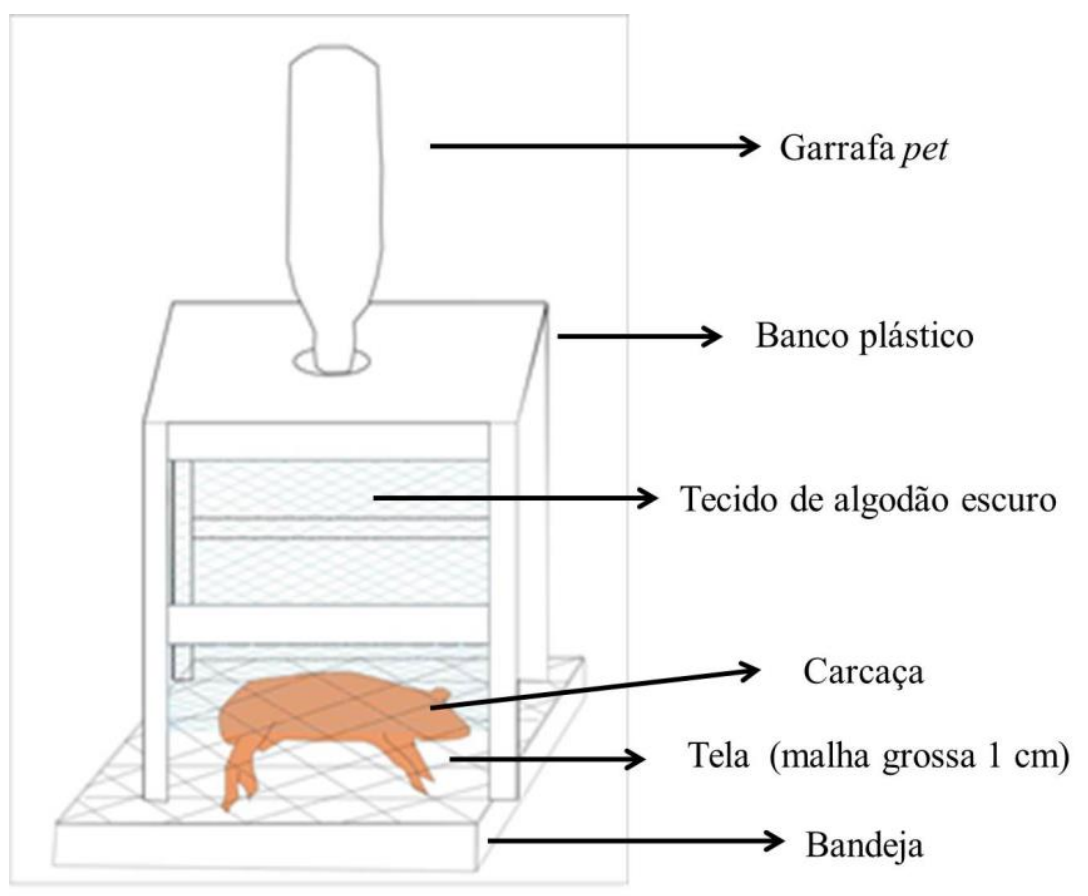

Figura 3. Armadilha utilizada para coleta dos dípteros adultos.

As coletas dos imaturos e adultos de dípteros, bem como o monitoramento das carcaças foram realizadas diariamente (9-14h) até que o último estágio de decomposição fosse observado e não houvesse mais presença de insetos na carcaça. Os dípteros coletados foram armazenados em potes etiquetados com a data, local e porco amostrado e encaminhados para o Laboratório de Entomologia Forense da UnB, para 
posterior triagem e identificação dos mesmos. A coleta dos imaturos foi realizada diariamente, sendo coletada uma amostra destes em várias partes da carcaça. Após cada coleta, as larvas foram triadas e separadas ao nível de família, sendo posteriormente transferidas para potes contendo uma dieta artificial de acordo com Estrada et al. (2009) a fim de acompanhar todo o desenvolvimento do imaturo até a emergência do adulto. Apenas as larvas da espécie Chrysomya albiceps (Wiedemann 1819) foram colocados em potes de dietas separados devido ao hábito predatório. Posteriormente, os potes de dietas foram colocados dentro de outro recipiente maior, no qual continha vermiculita e armazenados em uma câmara de incubação (Marconi ${ }^{\circledR}$ ) nesta faixa de temperatura (25 $\left.{ }^{\circ} \mathrm{C}\right)$ e umidade (70\%). A vermiculita serve como substrato para quando as larvas abandonarem a dieta em busca de um local para pupação. As pupas coletadas foram colocadas diretamente na vermiculita. O monitoramento dos potes criadouros foi realizado diariamente até a emergência dos adultos.

Desta forma, os procedimentos realizados no campo em cada carcaça foram na ordem: 1) fotografar a carcaça; 2) coleta dos dípteros adultos (troca das garrafas pet); 3) observações a respeito do estágio de decomposição e da atividade e comportamento dos dípteros na carcaça; 4) coleta ativa de imaturos (larvas e pupas) com o auxílio de pinças entomológicas e; 5) mensurar as variáveis climáticas do local (temperatura e umidade relativa do ar). Para a realização destes procedimentos em cada carcaça foi estipulado um tempo de 15 minutos.

A identificação dos dípteros necrófagos adultos pertencentes às famílias Calliphoridae e Sarcophagidae foi até o nível taxonômico de espécie usando chaves de identificação (Buenaventura e Pape 2013; Kosmann et al. 2013). Entretanto, para a família Sarcophagidae a identificação dos indivíduos se baseou apenas em estruturas da terminália dos espécimes machos. Os exemplares fêmeas da família Sarcophagidae 
foram separados em cinco morfótipos de acordo com o seu comprimento desde a cabeça até o último segmento abdominal. Assim, o morfótipo 1 abrange os indivíduos que variam de 1 - 3 mm, morfótipo 2 de 3,1 - 4,9 mm, morfótipo 3 de 5 - 7,9 mm, morfótipo 4 de $8-9,9 \mathrm{~mm}$ e morfótipo 5 os indivíduos maiores que $10 \mathrm{~mm}$.

Para os demais insetos coletados a identificação para alguns grupos foi até o nível taxonômico de gênero/espécie de acordo com chaves de identificação (Carvalho e Mello-Patiu 2008; Almeida e Mise 2009; Rafael et al. 2012). Porém, devido a grande variação existente dentro da classe Insecta, a identificação de alguns exemplares foi apenas até o nível de ordem (p. ex., Lepidoptera) e outros ao nível de família (p. ex., Muscidae, Fanniidae). Além disso, para a identificação de algumas famílias, gêneros e espécies foi necessário auxílio de especialistas. Posteriormente, parte do material coletado foi etiquetado e depositado na Coleção Entomológica de Zoologia da Universidade de Brasília.

Estágios de decomposição e comunidade de artrópodos visitantes

Foram considerados cinco estágios de decomposição de acordo com Smith (1986): fresco, inchaço, decomposição ativa, decomposição avançada e seco. Com isso, as particularidades consideradas para caracterizar cada estágio foram: (1) fresco, tem início no momento da morte, através das atividades de bactérias no interior do corpo; (2) inchaço, ocorre a partir da produção de gases por bactérias intestinais que inflam o corpo. Há um aumento na temperatura corporal devido à atividade de larvas que se alimentam de tecidos moles; (3) decomposição ativa, esta fase inicia-se através do rompimento do tecido externo devido à ação das larvas, permitindo a saída dos gases e consequentemente o esvaziamento do corpo. Uma característica marcante desta fase é a presença de grande massa larval de Diptera; (3) decomposição avançada, caracteriza-se 
por uma redução da atividade dos insetos, devido ao fato de que a maior parte da biomassa já foi consumida e a carcaça fica reduzida à pele e cartilagem; (4) seco, ocorre o ressecamento total da carcaça, restando apenas pelos e ossos (Smith 1986). Desta forma, com as mudanças nas características da carcaça podemos reconhecer quatro categorias ecológicas presentes na carcaça ao longo do processo de decomposição de acordo com a comunidade de artrópodos visitantes: (1) necrófagos, são aqueles que se alimentam diretamente da carcaça, seja na forma imatura ou adulta (p.ex., moscas e besouros); (2) predadores ou parasitas, parasitam e predam as espécies necrófagas (p.ex., besouros e vespas); (3) onívoros, alimentam-se da carcaça e dos artrópodes associados (p.ex., vespas, formigas e besouros); (4) acidentais, são as espécies que não utilizam o recurso para sua sobrevivência, apenas a usam como uma extensão do seu habitat ou como abrigo (p.ex., aranhas, centopeias e ácaros; Smith 1986). Neste trabalho foram coletados insetos pertencentes às quatro categorias ecológicas descritas acima (Tabelas 1-2). Entretanto consideramos apenas as espécies de dípteros necrófagos pertencentes às famílias Calliphoridae e Sarcophagidae identificadas até o nível de espécie, visto que a contribuição e participação de alguns grupos de insetos (Lepidoptera, Hemiptera, Orthoptera, Isoptera) no processo de decomposição e nos padrões de sucessão não estão claros na literatura.

\section{Análise dos dados}

Para avaliar a primeira pergunta (i.e. há diferença na duração do processo de decomposição e na duração dos estágios de decomposição (em dias) entre as duas fitofisionomias) foram realizados testes $t$ de Student, considerando a variância igual entre os grupos. As premissas de normalidade (teste de Shapiro) e homocedasticidade (teste de Bartlett) dos dados foram testadas antes da realização das análises (Legendre e 
Legendre 2012). Para testar se a duração da decomposição está relacionada às variáveis ambientais (temperatura e umidade relativa do ar) foi realizada uma regressão linear simples entre a temperatura do ar e a duração da decomposição em ambas as fitofisionomias. Antes dessa análise, foi testada a correlação entre as variáveis temperatura e umidade relativa do ar e optou-se por usar apenas a temperatura para as análises devido a forte correlação existente $(r=-0,91 ; P<0,001)$. Para testar as diferenças na temperatura e na umidade entre as fitofisionomias foram realizados testes $t$ de Student, considerando a variância igual entre os grupos. Para testar se havia diferença na biomassa inicial das carcaças entre as fitofisionomias foi realizado um teste $t$ de Student.

Para testar a segunda pergunta (i.e. a composição de dípteros necrófagos nas carcaças da mata de galeria difere das do cerrado sensu stricto) foi realizada uma análise multivariada de variância com permutações (PERMANOVA; Legendre e Legendre 2012) com o tempo como um cofator (i.e. strata). Para essa análise foi utilizada uma matriz de presença e ausência das espécies de dípteros necrófagos que colonizaram as carcaças em cada dia amostral em cada fitofisionomia. Para testar a quarta pergunta (i.e. há sucessão da fauna de dípteros necrófagos durante o processo de decomposição das carcaças nos duas fitofisionomias) foi realizada uma PERMANOVA para cada ambiente, considerando os dípteros como a variável resposta multivariada e o tempo (número de dias) como a variável preditora. A matriz utilizada nessas análises foram às mesmas da hipótese dois. Essas análises foram realizadas com a função adonis do pacote Vegan (Oksanen et al. 2013) do R (R Core Team 2013).

Para observar se o processo de sucessão apresenta limites discretos (i.e. a composição da comunidade de dípteros deve apresentar uma fauna distinta para cada estágio de decomposição; ou seja, haverá o agrupamento das amostras de acordo com o 
estágio de decomposição; Moura et al. 2005) ou é um contínuo de mudanças graduais (i.e. a composição da comunidade de dípteros não apresenta uma fauna distinta para cada estágio de decomposição; ou seja, as amostras de cada estágio de decomposição não são agrupadas, pois há mudanças graduais na composição de espécies dentro de cada estágio de decomposição; Moura et al. 2005) foram realizadas análises de agrupamento. As análises foram realizadas com matrizes de similaridade calculadas com o coeficiente de Jaccard (a partir de matrizes de presença e ausência) e com o uso do método de ligação UPGMA.

Para identificar espécies de dípteros necrófagos potencialmente indicadores dos estágios de decomposição foram realizadas análises de espécies indicadoras (Dufrêne e Legendre 1997). Para essa análise foram utilizadas matrizes de presença e ausência das espécies de dípteros para cada fitofisionomia. Essa análise quantifica a fidelidade (i.e. em quantas amostras de um determinado grupo a espécie ocorre) e a especificidade (i.e. exclusividade da espécie a um grupo em particular) da espécie em relação a um grupo de locais. Para avaliar estatisticamente a significância do valor de indicação (IndVal) são realizados testes de Monte Carlo, com 10.000 aleatorizações. Todas as análises foram realizadas no programa $\mathrm{R}$ ( $\mathrm{R}$ Core Team 2013), exceto a análise de espécies indicadoras que foi desenvolvida no PC-ORD® (McCune e Mefford 2011). Além disso, para a análise dos dados foram considerados todos os imaturos que completaram o desenvolvimento em laboratório e a espécie foi identificada, além dos adultos coletados em campo. 


\section{Resultados}

Tempo e estágios de decomposição das carcaças

As carcaças expostas no cerrado sensu stricto foram decompostas mais rapidamente do que as carcaças da mata de galeria (em média 10 dias no cerrado sensu stricto e 13 dias na mata de galeria; $t_{7,45}=3,23 ; P=0,013$ ). A temperatura foi responsável por $57 \%$ da variação na duração do processo de decomposição entre as fitofisionomias $\left(\mathrm{F}_{1 ; 10}=13,56 ; P=0,004 ; \mathrm{R}^{2}=57 \%\right)$. Houve uma relação negativa entre a temperatura do ar e a duração do processo de decomposição $\left(\mathrm{F}_{1 ; 10}=13,56 ; P=0,004\right.$; Figura 4). Desta forma, áreas que apresentam maiores temperaturas (e.g. cerrado sensu stricto) promovem uma diminuição no número de dias necessário para a carcaça se decompor (Figura 4). As áreas do cerrado sensu stricto apresentaram maior temperatura e menor umidade média $\left(31,5^{\circ} \mathrm{C} \pm 1,4 ; 43,3 \% \pm 1,4\right)$ quando comparadas às áreas de mata de galeria $\left(27,1^{\circ} \mathrm{C} \pm 1,2 ; 53,2 \% \pm 5,2\right)$.

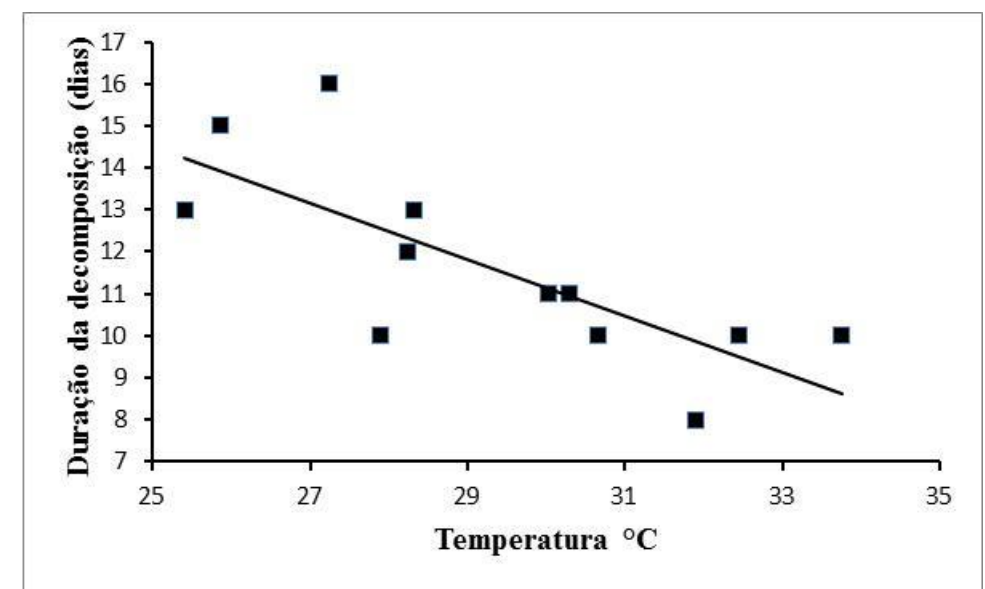

Figura 4. Regressão linear entre a temperatura do ar e a duração do processo de decomposição (em dias) nas fitofisionomias de mata de galeria e cerrado sensu stricto. 
Foram observados quatro estágios de decomposição: fresco, decomposição ativa, decomposição avançada e seco (Figura 5-6). Na fitofisionomia de mata de galeria o estágio fresco apresentou uma duração média de $2 \pm 0$ dia enquanto no cerrado sensu stricto a média foi de $1 \pm 0$ dia. Para o estágio de decomposição ativa a duração média foi de $8 \pm 2$ dias na mata de galeria, enquanto no cerrado sensu stricto foi de $6 \pm 1$ dia. Para os estágios de decomposição avançada e seco a duração média das fases foi igual nas duas fitofisionomias sendo de $2 \pm 1$ e $1 \pm 1$ dia, respectivamente. Todavia, houve diferença no número de dias que as carcaças permaneceram no estágio fresco $\left(t_{10}=\right.$ 2,23; $P=0,049)$ e em decomposição ativa $\left(t_{10}=2,53 ; P=0,045\right)$ entre as fitofisionomias. Ambos os estágios (fresco e de decomposição ativa) foram mais prolongados na mata de galeria do que no cerrado sensu stricto.
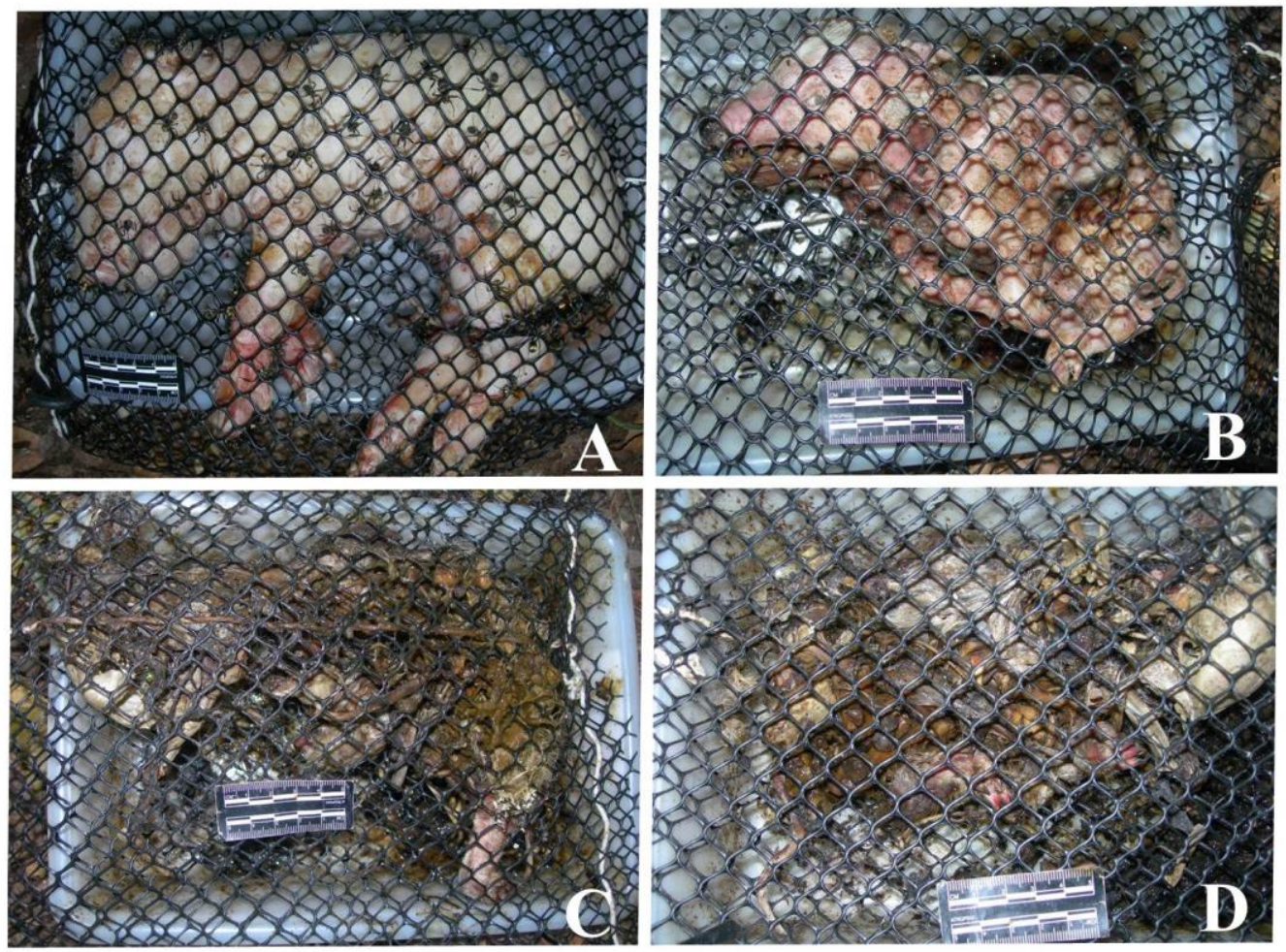

Figura 5. Estágios de decomposição fresco (A), decomposição ativa (B), decomposição avançada (C) e, seco (D) observados nas carcaças expostas na mata de galeria. 

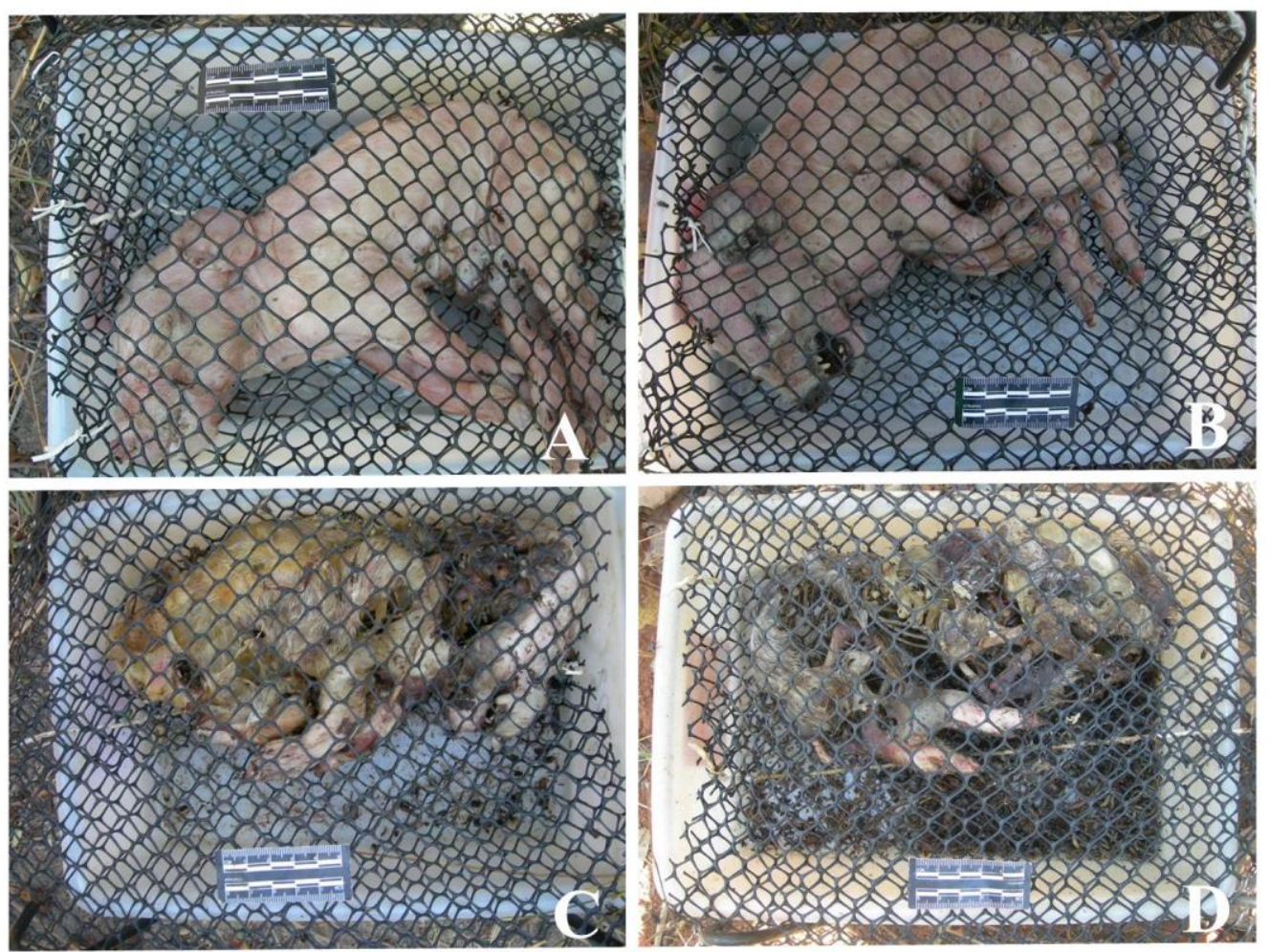

Figura 6. Estágios de decomposição fresco (A), decomposição ativa (B), decomposição avançada (C) e, seco (D) observados nas carcaças expostas no cerrado sensu stricto.

Composição e sucessão de dípteros necrófagos nas carcaças

Foi coletado um total de 7.209 insetos representando seis ordens associados às carcaças em ambas fitofisionomias (Tabela 1-2). Deste total, 2.867 são califorídeos e 1.167 são representantes da família Sarcophagidae. Foram identificados 16 espécies de dípteros pertencentes às famílias Sarcophagidae e Calliphoridae (Figura 7-8), sendo que doze espécies ocorreram nas duas fitofisionomias (Tabelas 4-5). As carcaças de mata de galeria e cerrado sensu stricto apresentaram uma riqueza total de 14 espécies para cada fitofisionomia (Tabelas 4-5). As espécies de califorídeos mais abundantes independente da fitofisionomia foram C. albiceps (2.156 indivíduos), Lucilia eximia (524 indivíduos) Chloroprocta idioidea (109 indivíduos). Enquanto para a família Sarcophagidae foram Peckia intermutans (195 indivíduos), Oxysarcodexia 
thornax (Walker, 1849; 103 indivíduos) e Peckia ingens (Walker, 1849; 93 indivíduos). Além disso, podemos observar a ocorrência de espécies características de um determinado ambiente. As espécies Peckia pexata (Wulp, 1895) e Peckia trivittata (Curran, 1927) ocorreram somente no cerrado sensu stricto, enquanto Mesembrinella bicolor (Fabricius, 1805) e Hemilucilia semidiaphana (Rondani, 1850) ocorreram apenas na mata de galeria (Tabelas 4-5). A espécie mais frequente em ambos os ambientes foi Chrysomya albiceps (Tabelas 6-7). 
TABELA 1. Frequência relativa de insetos ao longo dos estágios de decomposição $(F=$ fresco, $A T=$ decomposição ativa, $\mathrm{AV}=$ decomposição avançada $\mathrm{e}, \mathrm{S}=$ seco) em carcaças expostas na mata de galeria. A frequência relativa se baseia no número de ocorrência de cada táxon nas carcaças durante os dias do experimento. As barras contínuas $(\longmapsto$ ) indicam a variação mínima e máxima na duração dos estágios de decomposição (em dias) entre as carcaças.

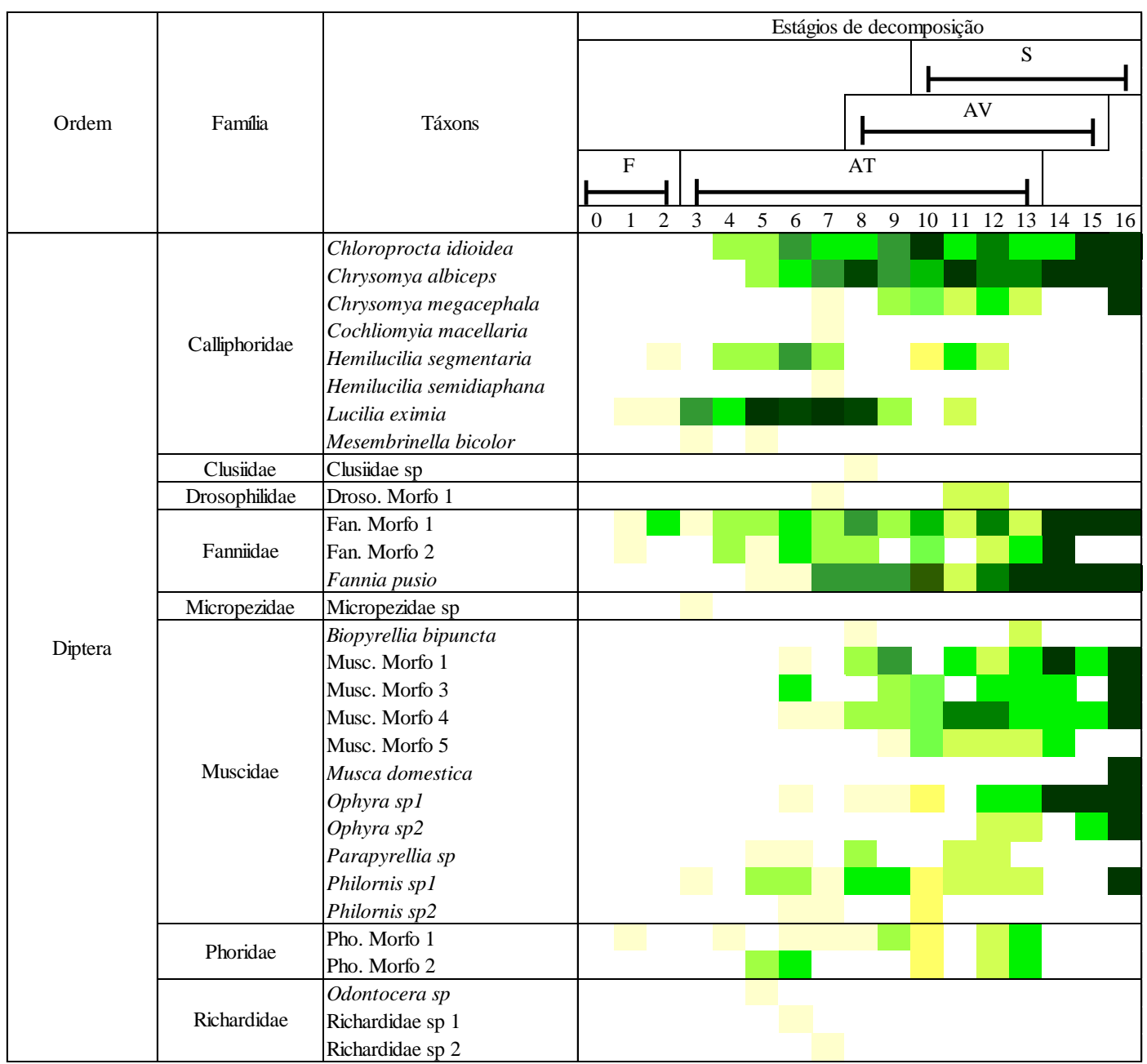

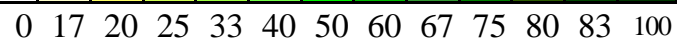

Frequência relativa $(\%)$ 


\section{Continuação Tabela 1}

TABELA 1. Frequência relativa de insetos ao longo dos estágios de decomposição $(\mathrm{F}=$ fresco, $\mathrm{AT}=$ decomposição ativa, AV = decomposição avançada e, $\mathrm{S}=$ seco) em carcaças expostas na mata de galeria. A frequência relativa se baseia no número de ocorrência de cada táxon nas carcaças durante os dias do experimento. As barras contínuas ( decomposição (em dias) entre as carcaças.

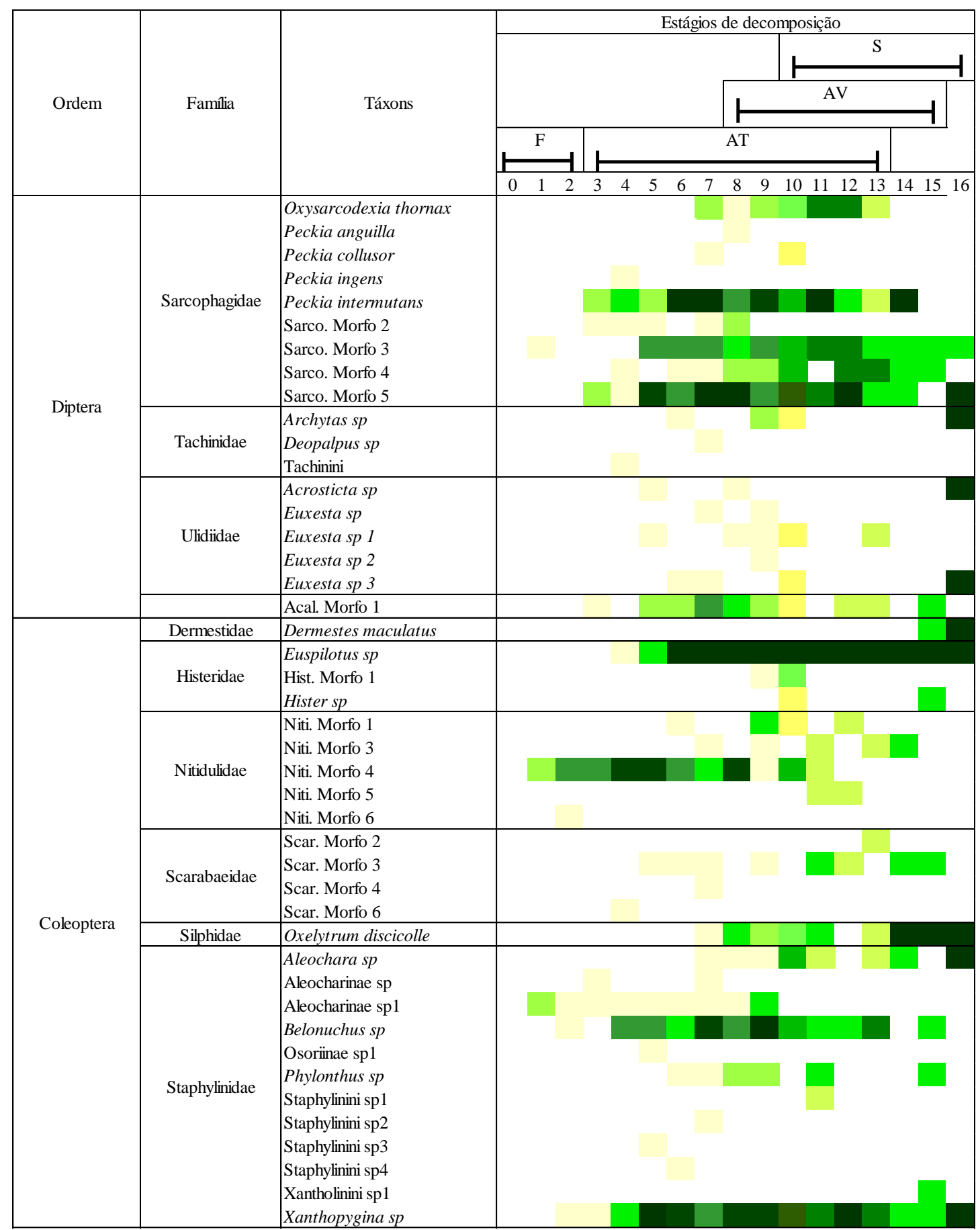

$\begin{array}{lllllllllllll}0 & 17 & 20 & 25 & 33 & 40 & 50 & 60 & 67 & 75 & 80 & 83 & 100\end{array}$ Frequência relativa (\%) 


\section{Continuação Tabela 1}

TABELA 1. Frequência relativa de insetos ao longo dos estágios de decomposição $(\mathrm{F}=$ fresco, $\mathrm{AT}=$ decomposição ativa, $\mathrm{AV}=$ decomposição avançada e, $\mathrm{S}=$ seco) em carcaças expostas na mata de galeria. A frequência relativa se baseia no número de ocorrência de cada táxon nas carcaças durante os dias do experimento. As barras contínuas $(\longmapsto$ ) indicam a variação mínima e máxima na duração dos estágios de decomposição (em dias) entre as carcaças.

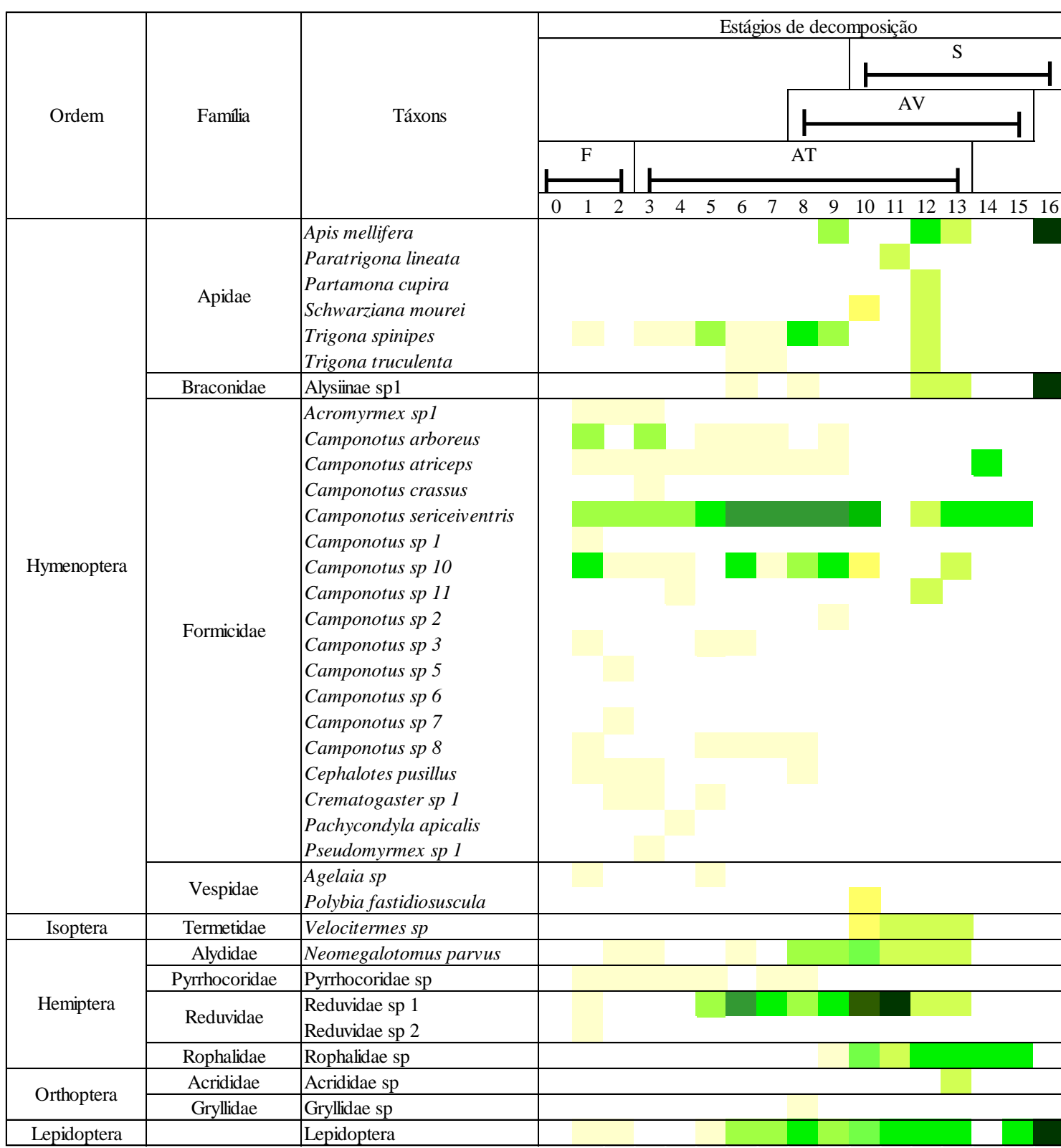

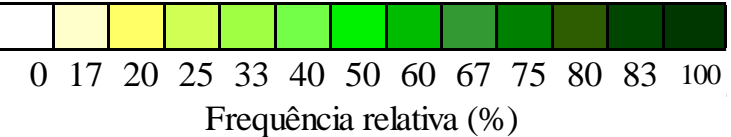


TABELA 2. Frequência relativa de insetos ao longo dos estágios de decomposição ( $\mathrm{F}=$ fresco, $\mathrm{AT}=$ decomposição ativa, $\mathrm{AV}=$ decomposição avançada e, $\mathrm{S}=$ seco) em carcaças expostas no cerrado sensu stricto. A frequência relativa se baseia no número de ocorrência de cada táxon nas carcaças durante os dias do experimento. As barras contínuas $(\longmapsto$ ) indicam a variação mínima e máxima na duração dos estágios de decomposição (em dias) entre as carcaças.

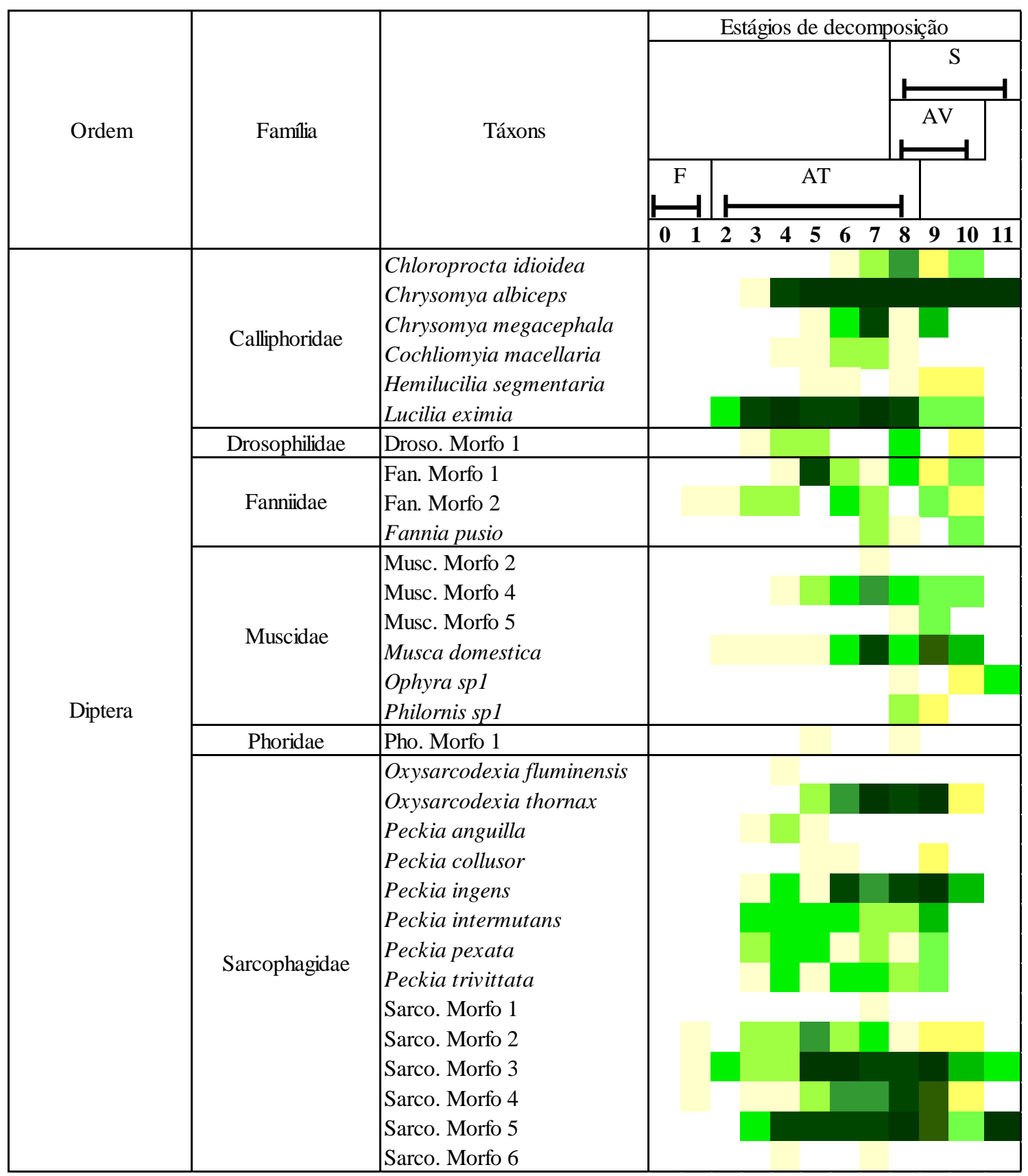

$\begin{array}{lllllllllllll}0 & 17 & 20 & 25 & 33 & 40 & 50 & 60 & 67 & 75 & 80 & 83 & 100\end{array}$ Frequência relativa (\%) 


\section{Continuação Tabela 2}

TABELA 2. Frequência relativa de insetos ao longo dos estágios de decomposição $(\mathrm{F}=$ fresco, $\mathrm{AT}=$ decomposição ativa, AV = decomposição avançada e, $\mathrm{S}=$ seco) em carcaças expostas no cerrado sensu stricto. A frequência relativa se baseia no número de ocorrência de cada táxon nas carcaças durante os dias do experimento. As barras contínuas ( $\longrightarrow$ ) indicam a variação mínima e máxima na duração dos estágios de decomposição (em dias) entre as carcaças.

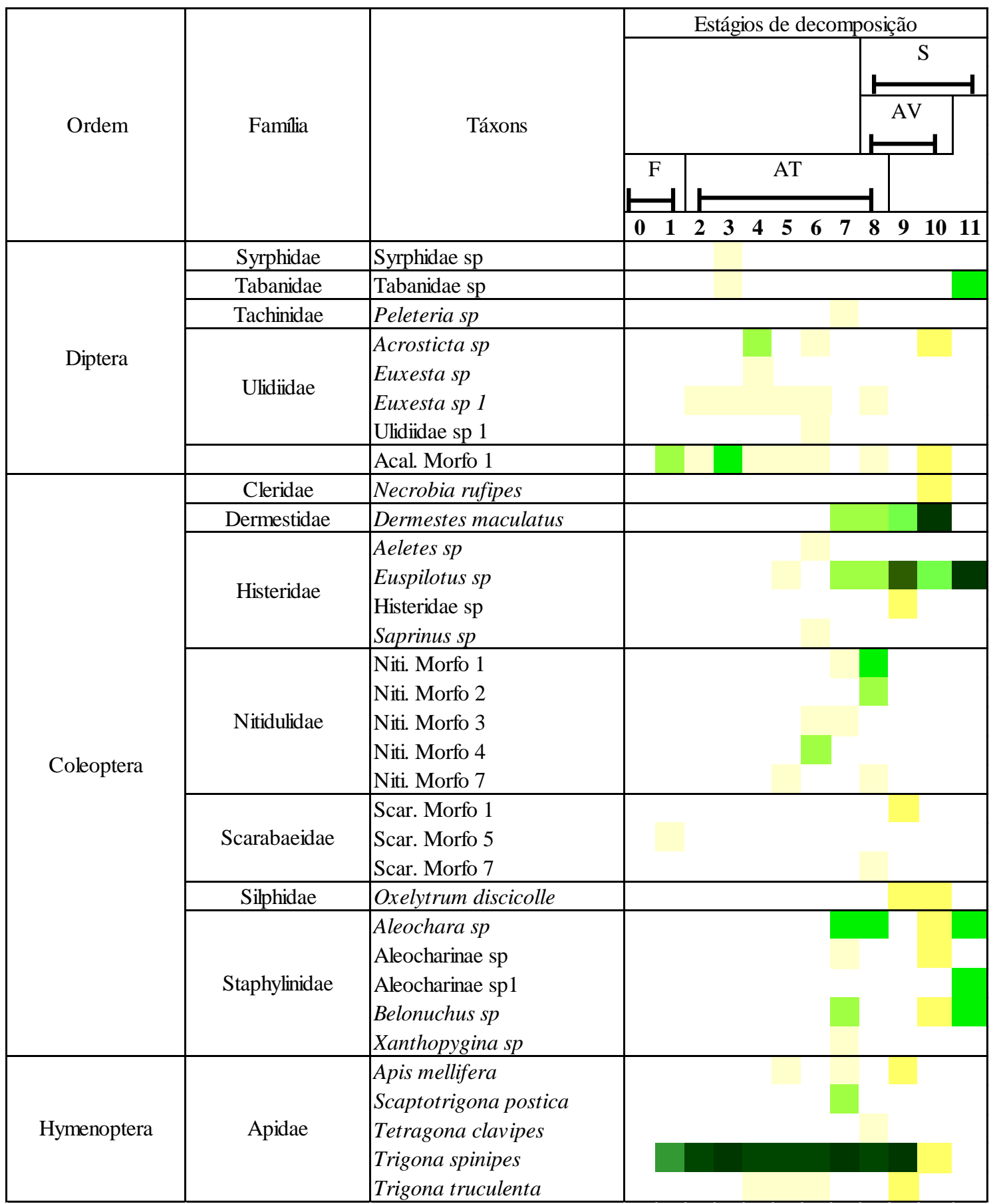

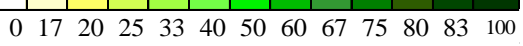
Frequência relativa $(\%)$ 


\section{Continuação Tabela 2}

TABELA 2. Frequência relativa de insetos ao longo dos estágios de decomposição $(\mathrm{F}=$ fresco, AT $=$ decomposição ativa, $\mathrm{AV}=$ decomposição avançada e, $\mathrm{S}=$ seco) em carcaças expostas no cerrado sensu stricto. A frequência relativa se baseia no número de ocorrência de cada táxon nas carcaças durante os dias do experimento. As barras contínuas ( estágios de decomposição (em dias) entre as carcaças.

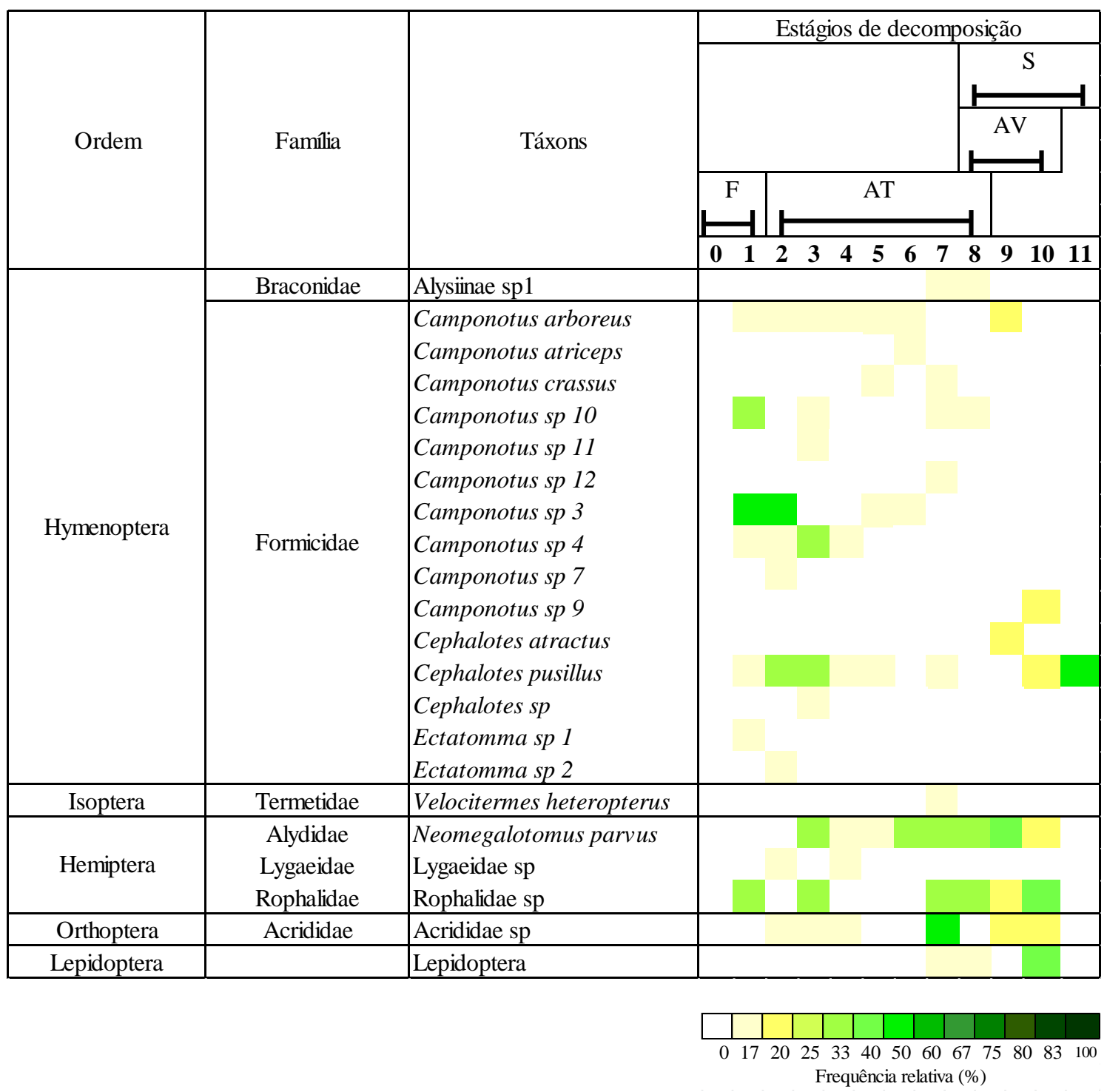




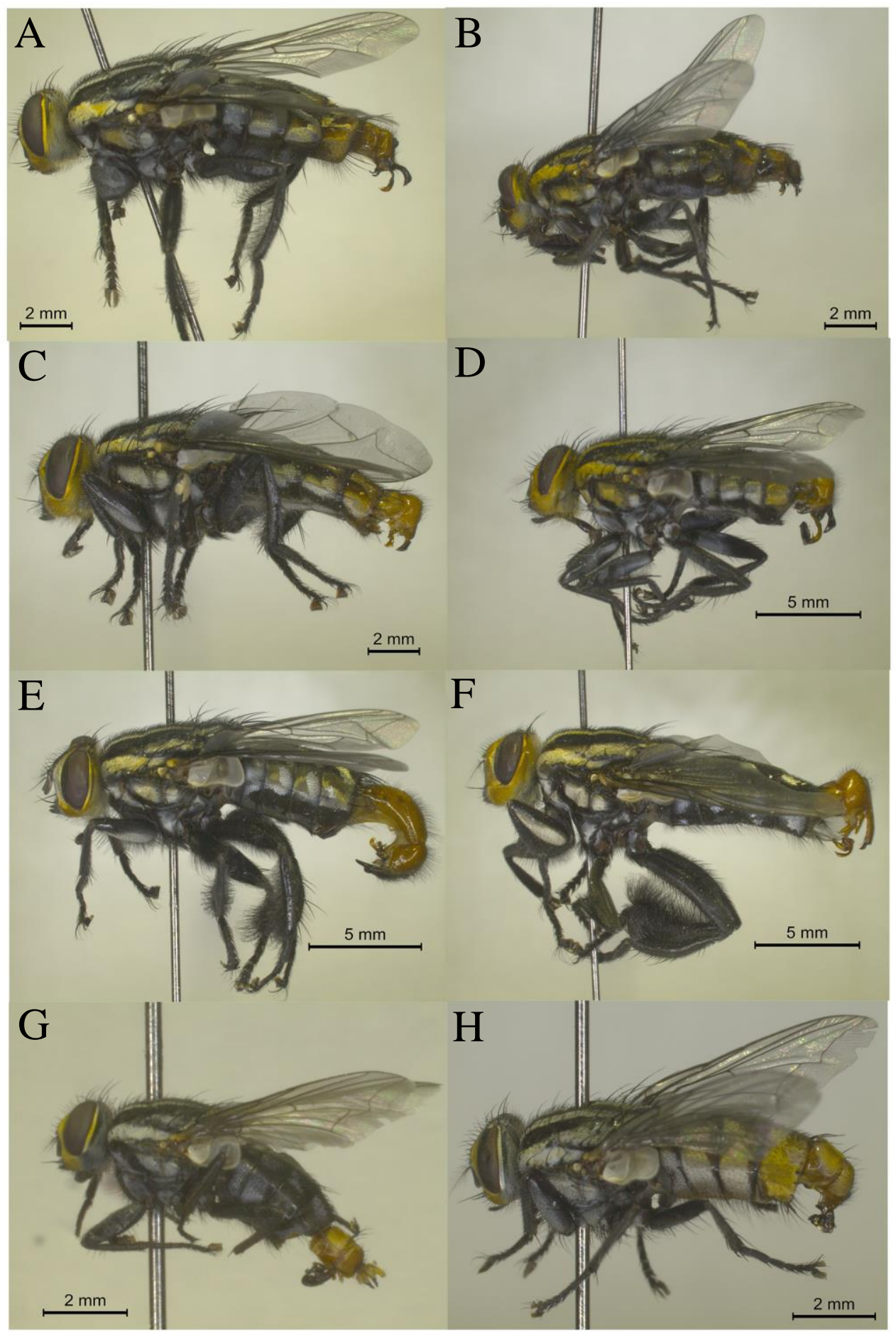

Figura 7. Espécies de dípteros pertencentes à família Sarcophagidae (letras $\mathrm{A}$ à $\mathrm{H}$ ) registradas ao longo do processo de decomposição. As letras indicam as espécies: A (Peckia anguilla), B (Peckia collusor), C (Peckia ingens), D (Peckia intermutans), E (Peckia pexata), F (Peckia trivittata), G (Oxysarcodexia fluminensis), e H (Oxysarcodexia thornax). 


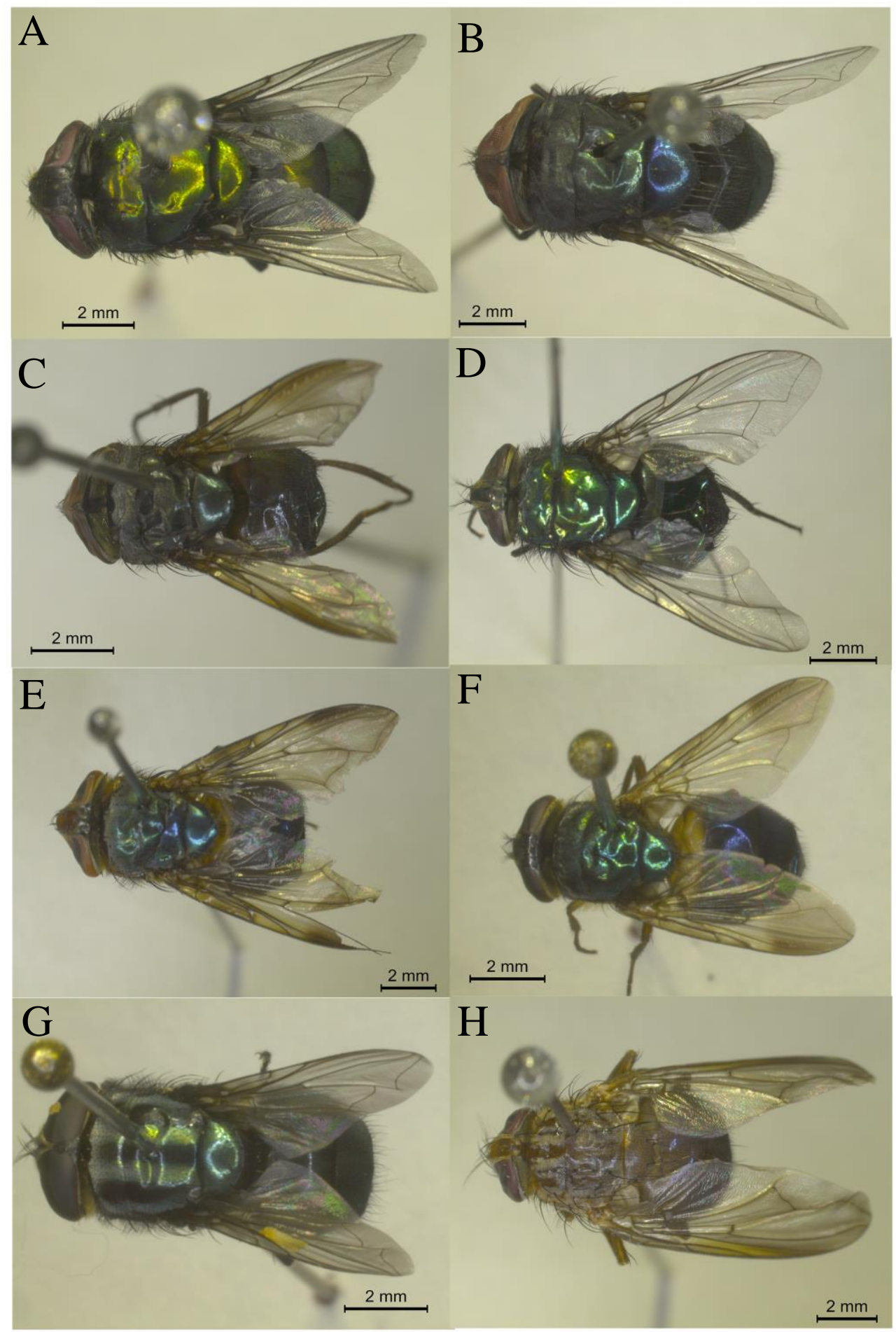

Figura 8. Espécies de dípteros pertencentes à família Calliphoridae (letras $\mathrm{A}$ à $\mathrm{H}$ ) registradas ao longo do processo de decomposição. As letras indicam as espécies: A (Chrysomya albiceps), B (Chrysomya megacephala), C (Chloroprocta idioidea), D (Lucilia eximia), E (Hemilucilia segmentaria), F (Hemilucilia semidiaphana), G (Cochliomyia macellaria) e H (Mesembrinella bicolor).

A composição de espécies de dípteros necrófagos associada às carcaças diferiu entre as fitofisionomias de mata de galeria e cerrado sensu stricto (PERMANOVA: 
$\left.\mathrm{F}_{1 ; 113}=12,19, P=0,001\right)$, sendo possível observar espécies indicadoras para alguns estágios de decomposição para os dois ambientes (Tabela 3). Para o estágio fresco na mata de galeria a espécie indicadora foi L. eximia, enquanto no cerrado sensu stricto obtemos C. idioidea e O. thornax como indicadoras do estágio de decomposição avançada e $C$. albiceps como indicadora da fase seca (Tabela 3).

Tabela 3. Espécies de dípteros indicadoras dos estágios de decomposição na fitofisionomia de mata de galeria (MG) e cerrado sensu stricto (SS). VI indica o valor de indicação das espécies.

\begin{tabular}{ccccc}
\hline Ambiente & Estágio de decomposição & Espécie & VI (\%) & $\boldsymbol{P}$ \\
\hline MG & Fresco & Lucilia eximia & 55 & 0,0002 \\
SS & Decomposição avançada & Chloroprocta idioidea & 32 & 0,0300 \\
SS & Decomposição avançada & Oxysarcodexia thornax & 48 & 0,0032 \\
SS & Seco & Chrysomya albiceps & 32 & 0,0016 \\
\hline
\end{tabular}

As fitofisionomias de mata de galeria e cerrado sensu stricto apresentaram sequência semelhante de espécies de dípteros ao longo do processo de decomposição, sendo possível observar sucessão destes dípteros nos dois ambientes (PERMANOVA: mata de galeria: $F_{1 ; 62}=18,20, P=0,001$; Tabela 5; cerrado sensu stricto: $F_{1 ; 50}=10,77$, $P=0,001$; Tabela 4). O colonizador primário nas duas fitofisionomias foi à espécie $L$. eximia. Representantes adultos desta espécie foram registrados nas carcaças de mata de galeria nas primeiras 24 horas de exposição, enquanto no cerrado sensu stricto esta foi observada após 48 horas de exposição (Tabelas 4-5). Nas duas fitofisionomias $L$. eximia apresentou maior frequência relativa no estágio de decomposição ativa (Tabelas 6-7). Da mesma forma, P. intermutans também colonizou as carcaças durante os primeiros dias nas duas fitofisionomias permanecendo até o início da fase de decomposição avançada nos dois ambientes (Tabelas 4-5). Caso semelhante ocorreu 
para a espécie $P$. ingens que colonizou as duas fitofisionomias no início do estágio de decomposição ativa, porém posteriormente foram registrados apenas no cerrado sensu stricto (Tabelas 4-5). Por outro lado, no cerrado sensu stricto observamos também como colonizadores primários das carcaças as espécies $P$. pexata, $P$. trivitatta e Peckia anguilla (Curran e Walley, 1934; Tabela 4). Enquanto na mata de galeria foram registradas as espécies M. bicolor e Hemilucilia segmentaria (Fabricius, 1805; Tabelas $5)$.

Colonizadores secundários para o cerrado sensu stricto observamos a presença das espécies C. idioidea, H. segmentaria, Chrysomya megacephala (Fabricius, 1754), C. albiceps, Cochliomyia macellaria (Fabricius, 1775), O. thornax, Oxysarcodexia fluminensis (Lopes, 1946) e Peckia collusor (Curran e Walley, 1934; Tabela 4). Na mata de galeria além das seis últimas espécies descritas acima $P$. anguilla, C. albiceps e H. semidiaphana foram também registradas nas carcaças como visitantes secundários (Tabela 5). Entretanto, as espécies $H$. semidiaphana, C. macellaria, O. fluminensis e $P$. anguilla foram registrados em um único dia na mata de galeria durante todo o experimento (Tabelas 5). Além disso, observamos que a espécie C. albiceps no cerrado sensu stricto manteve frequência elevada desde o início do estágio de decomposição ativa até o último dia do estágio seco (Tabela 6). Por outro lado, esta espécie na mata de galeria apresentou uma frequência variável entre os estágios intermediários, atingindo sua máxima frequência somente no final dos estágios de decomposição avançada e seco (Tabelas 7). A frequência relativa das demais espécies de dípteros foi variável entre os estágios de decomposição (Tabelas 6-7), com exceção apenas para as espécies de sarcofagídeos $O$. thornax e $P$. ingens que foram mais frequentes no final do estágio de decomposição ativa/início da fase de decomposição avançada no cerrado sensu stricto (Tabela 6). Contudo, no final dos estágios de decomposição avançada e seco algumas 
espécies (e.g. C. albiceps, C. megacephala, C. idioidea e P. intermutans) apresentaram elevada frequência nas duas fitofisionomias (Tabelas 6-7). 
TABELA 4. Matriz de ocorrência (presença/ausência) de dípteros necrófagos pertencentes às famílias Calliphoridae e Sarcophagidae associada às carcaças expostas no cerrado sensu stricto. As barras contínuas ( $\longrightarrow$ ) indicam a variação mínima e máxima na duração dos estágios de decomposição (em dias) entre as carcaças.

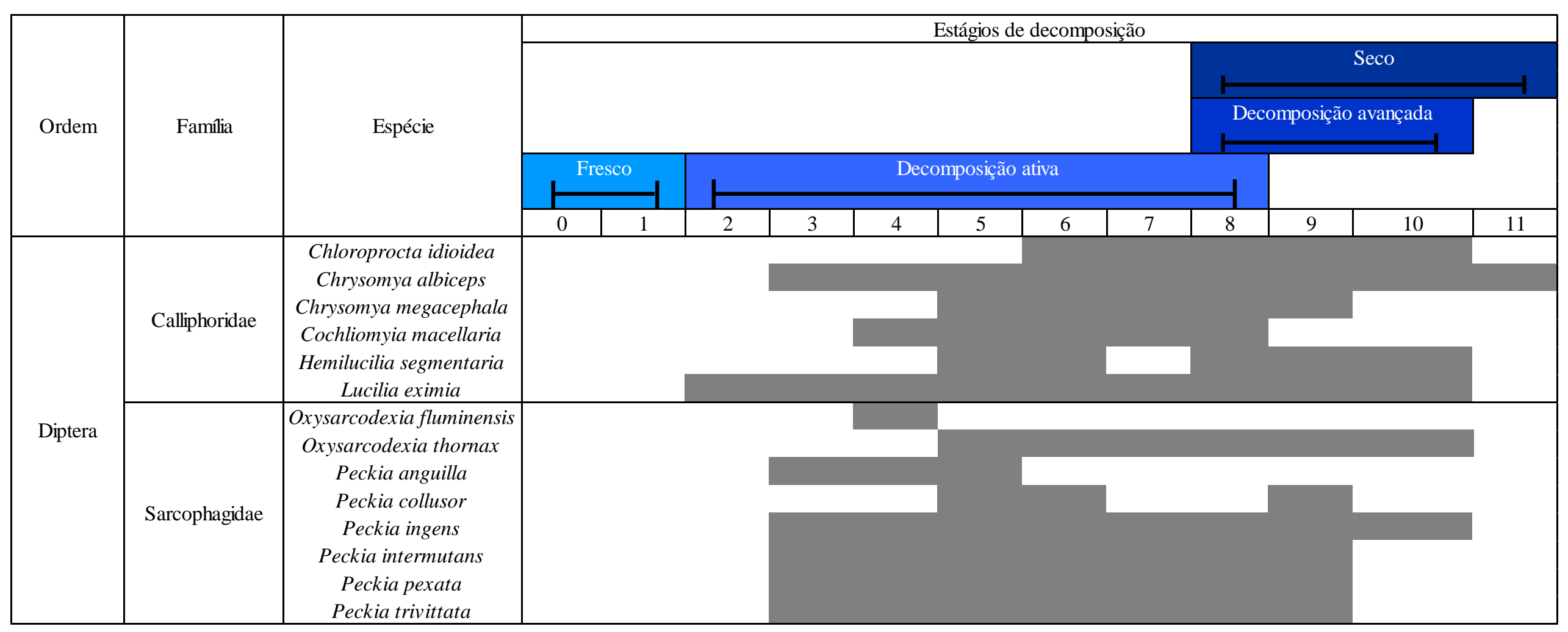


TABELA 5. Matriz de ocorrência (presença/ausência) de dípteros necrófagos pertencentes às famílias Calliphoridae e Sarcophagidae associada às carcaças expostas na mata de galeria. As barras contínuas (

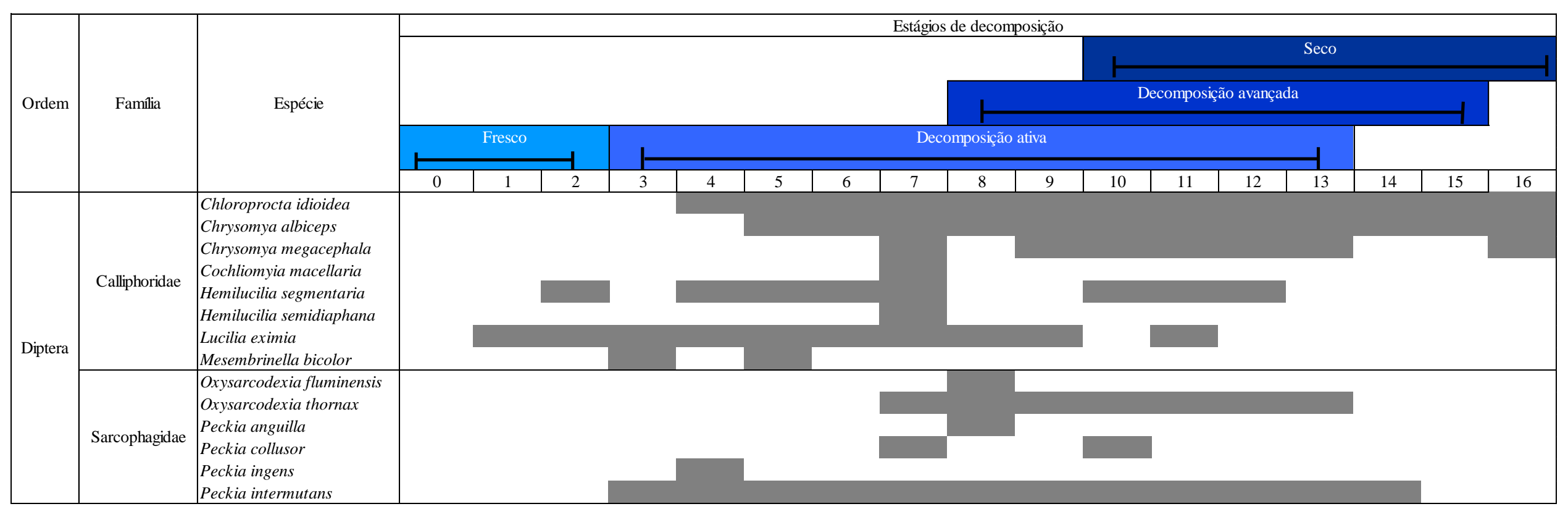


TABELA 6. Frequência relativa das espécies de dípteros necrófagos pertencentes às famílias Calliphoridae e Sarcophagidae ao longo dos estágios de decomposição ( $\mathrm{F}=$ fresco, AT = decomposição ativa, $\mathrm{AV}=$ decomposição avançada $\mathrm{e}, \mathrm{S}=$ seco) em carcaças expostas no cerrado sensu stricto. A frequência relativa se baseia no número de ocorrência de cada espécie nas carcaças durante os dias do experimento. As barras contínuas $(\longmapsto)$ indicam a variação mínima e máxima na duração dos estágios de decomposição (em dias) entre as carcaças.

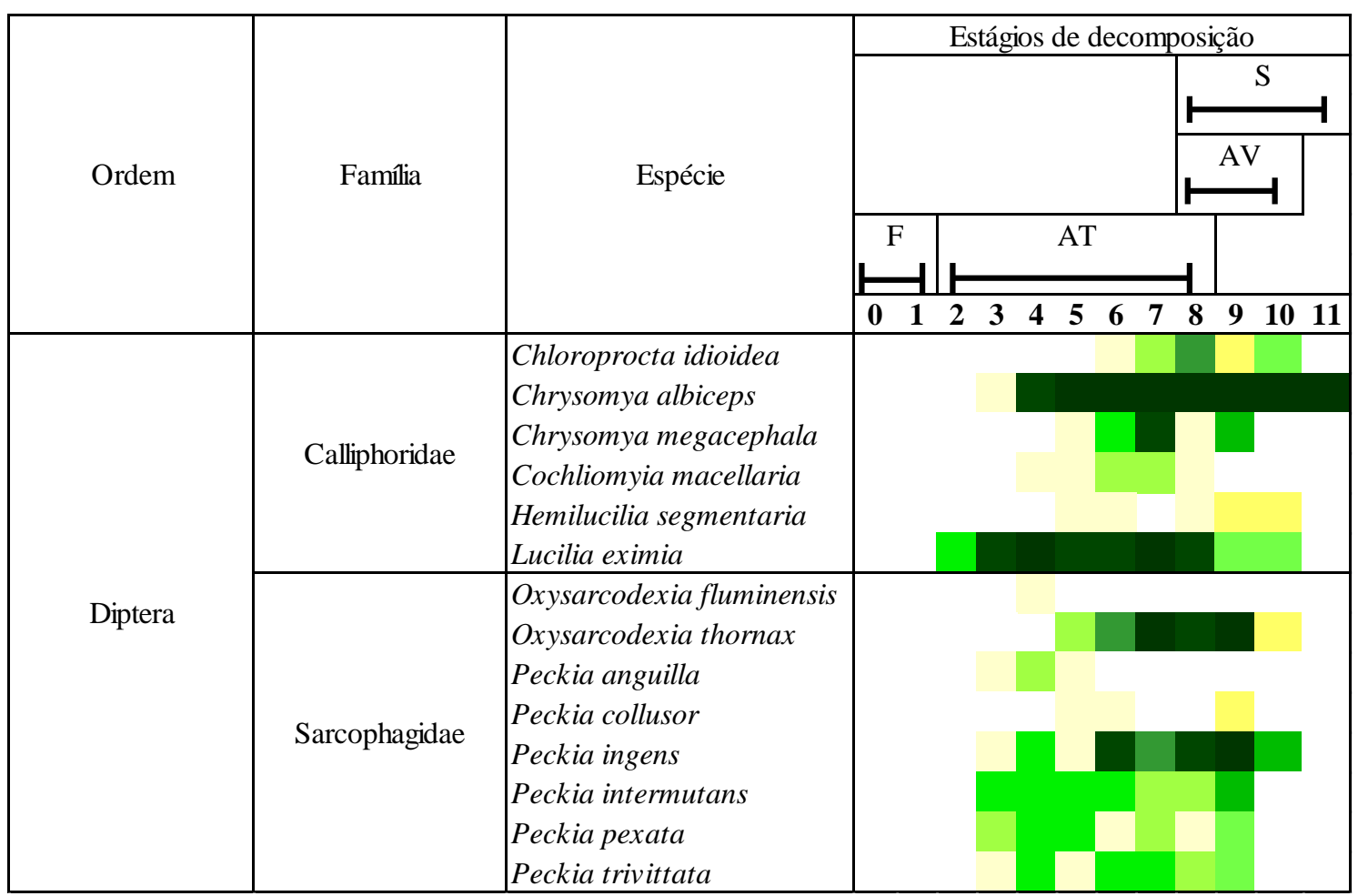

$\begin{array}{lllllllllllll}0 & 17 & 20 & 25 & 33 & 40 & 50 & 60 & 67 & 75 & 80 & 83 & 100\end{array}$ Frequência relativa $(\%)$ 
TABELA 7. Frequência relativa das espécies de dípteros necrófagos pertencentes às famílias Calliphoridae e Sarcophagidae ao longo dos estágios de decomposição ( $\mathrm{F}=$ fresco, AT = decomposição ativa, $\mathrm{AV}=$ decomposição avançada $\mathrm{e}, \mathrm{S}=\mathrm{seco}$ ) em carcaças expostas na mata de galeria. A frequência relativa se baseia no número de ocorrência de cada espécie nas carcaças durante os dias do experimento. As barras contínuas ( $\longrightarrow$ ) indicam a variação mínima e máxima na duração dos estágios de decomposição (em dias) entre as carcaças.

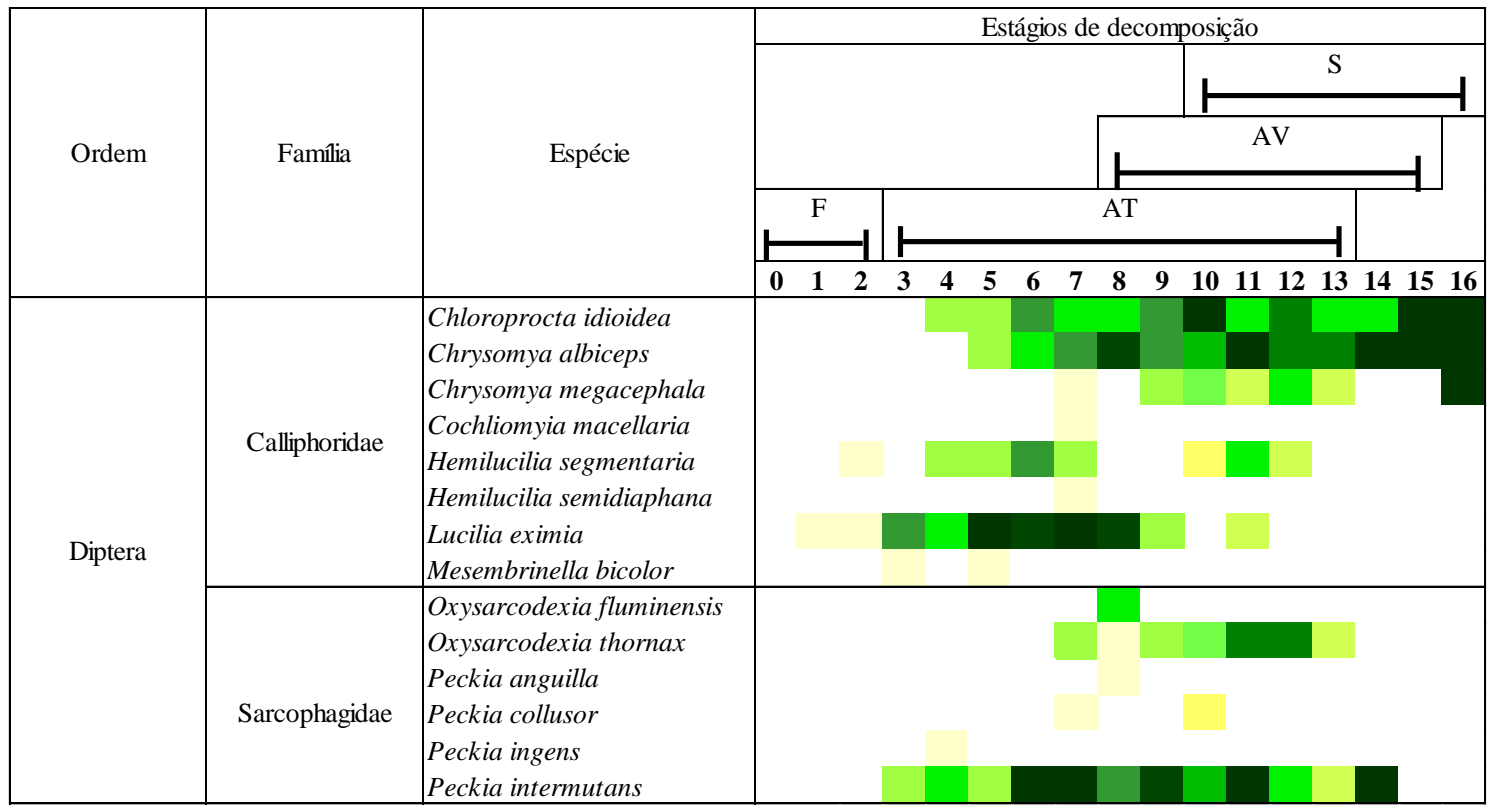

$\begin{array}{lllllllllllll}0 & 17 & 20 & 25 & 33 & 40 & 50 & 60 & 67 & 75 & 80 & 83 & 100\end{array}$ Frequência relativa $(\%)$

O processo de sucessão de dípteros foi semelhante entre as carcaças expostas nas duas fitofisionomias (Figura 9). A partir da análise de agrupamento, podemos observar a formação de três grupos na mata de galeria enquanto no cerrado sensu stricto houve formação de quatro grupos de acordo com a similaridade na composição de dípteros necrófagos (Figura 9A-B). Para a mata de galeria o primeiro grupo é formado pelos estágios de decomposição avançada e seco. O segundo grupo foi formado pelos estágios de decomposição ativa e avançada. O terceiro grupo foi formado pelos estágios fresco, decomposição ativa, avançada e seco (Figura 9A). Para o cerrado sensu stricto o primeiro grupo foi formado apenas com o estágio de decomposição ativa (Figura 9B). O segundo grupo foi formado pelos estágios de decomposição avançada e seco. O terceiro 
foi formado pelos estágios de decomposição ativa e avançada. O quarto grupo foi formado por dias dos estágios de decomposição ativa, avançada e seco (Figura 9B). Com isso, observamos que os grupos formados baseados na composição de dípteros não foram separados de acordo com os estágios de decomposição observados durante o experimento (Figura 9A-B). Desta forma, a fauna de dípteros necrófagos apresenta uma transição entre os estágios de decomposição, visto que não há uma composição distinta para cada fase (Figura 9A-B), com exceção apenas para o primeiro grupo do cerrado sensu stricto que apresentou uma fauna distinta, composto somente com o estágio de decomposição ativa (Figura 9B). 

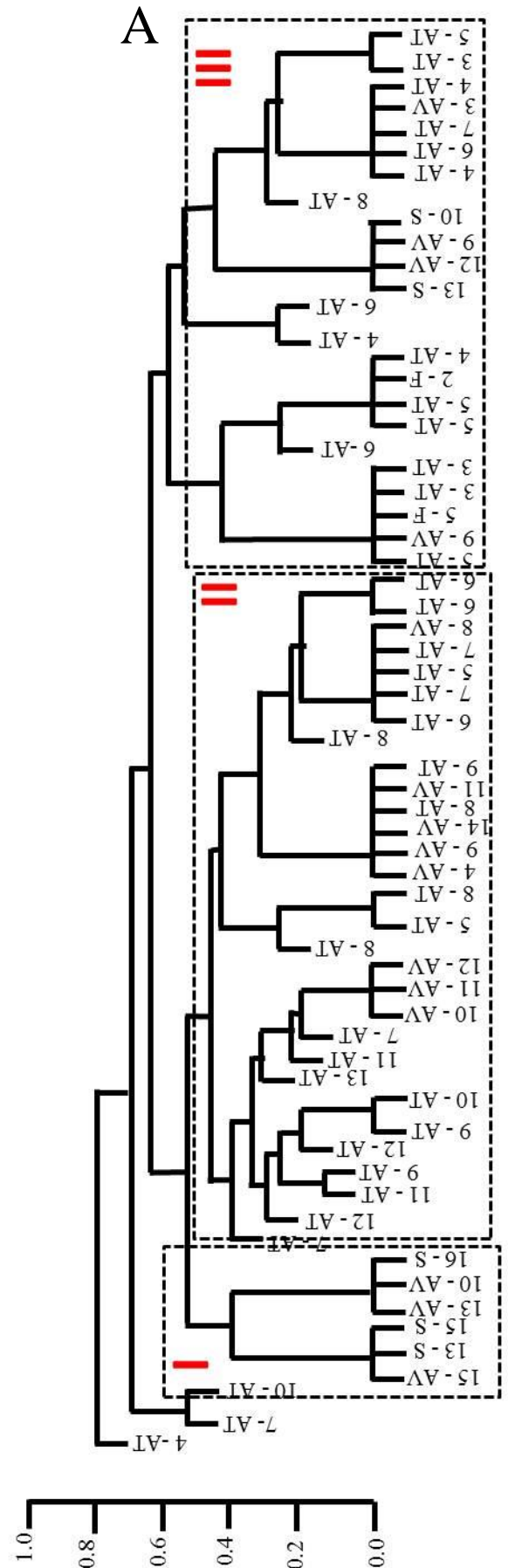

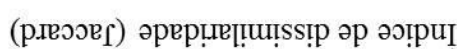

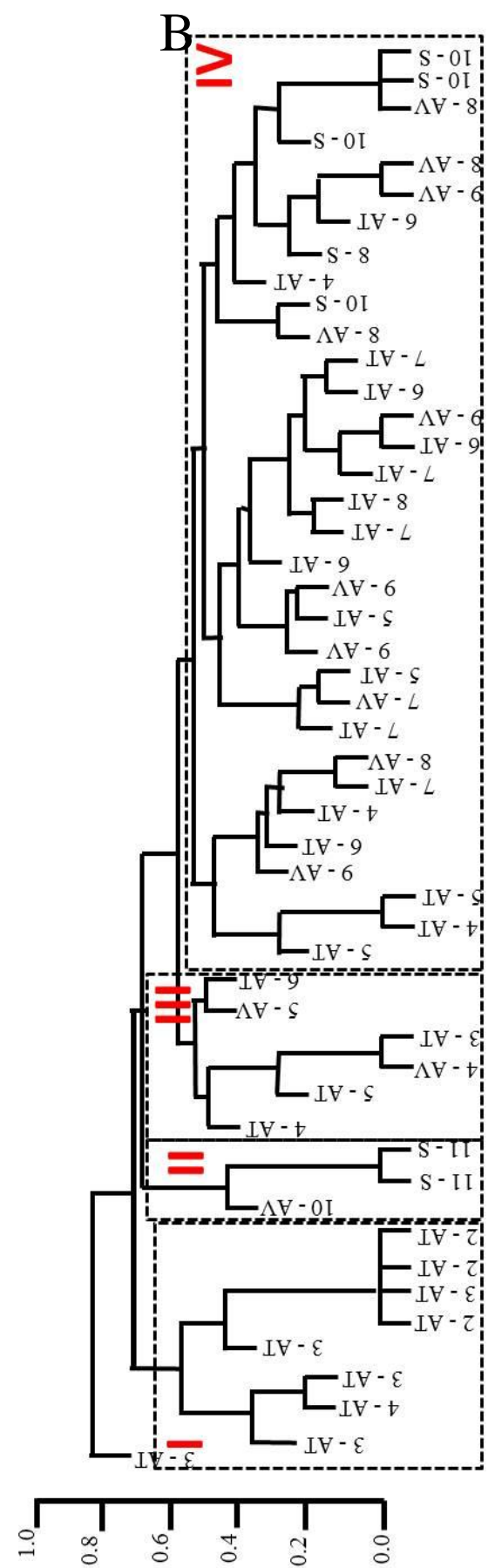

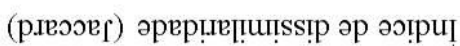

Figura 9. Análise de agrupamento da composição de dípteros necrófagos em carcaças expostas na mata de galeria (A) e no cerrado sensu stricto (B) considerando os estágios de decomposição (em dias). Os estágios de decomposição são indicados por: fresco (F), decomposição ativa (AT), decomposição avançada (AV) e, seco (S). Os números indicam o dia do experimento. Os números em romanos (I, II, III e IV) indicam os grupos formados para cada fitofisionomia. 


\section{Discussão}

Tempo e estágios de decomposição das carcaças

A duração do processo de decomposição (em dias) diferiu entre as duas fitofisionomias, sendo esta variação principalmente atribuída às diferenças nas variáveis microclimáticas (temperatura e umidade relativa do ar) de cada local. Diferenças observadas no microclima podem estar associadas a variações na estrutura da vegetação que são conhecidas por influenciar diretamente nas condições locais de cada ambiente (Campobasso et al. 2001; Eberhardt e Elliot 2008; Matuszewski et al. 2008; Sharanowski et al. 2008). Do mesmo modo, condições quentes e secas são conhecidas por promover uma maior atividade dos insetos, resultando em uma rápida diminuição da biomassa da carcaça (Bharti e Singh 2003; Sutherland et al. 2013), justificando a decomposição mais rápida no cerrado sensu stricto do que na mata de galeria.

Apesar de a decomposição ser um processo contínuo, esta é dividida em uma série de estágios que variam dependendo da descrição do entomologista e da região geográfica. Neste trabalho observamos a ocorrência de quatro estágios de decomposição (fresco, decomposição ativa, decomposição avançada e seco), enquanto em outros estudos o processo foi divido em cinco fases, tais como o de Moretti e colaboradores (2008), Rosa e colaboradores (2009; fase inicial, fase de putrefação, fase de putrefação escura, fase de fermentação e fase seca) e Biavati et al. (2010; inicial, inchaço, decaimento, pós decaimento e seco). Por outro lado, além da variação na descrição por parte do entomologista, a não observação de um quinto estágio (inchaço) pode ser atribuído ao uso de porcos natimortos, os quais apresentam microbiota menos diversa do que porcos maiores (Favier et al. 2002). Com isso, em carcaças de porcos natimortos o estágio de inchaço pode não ser observado, pois esta fase ocorre a partir da produção 
de gases por bactérias intestinais que inflam o corpo (Smith 1986). Além disso, diferenças associadas à maior duração dos estágios de decomposição fresco e de decomposição ativa no cerrado sensu stricto podem estar relacionadas às variações ambientais (umidade) que promoveram um prolongamento na duração dos estágios (e.g. Schoenly et al. 1996; Sutherland et al. 2013). Igualmente, após as primeiras 24 horas do experimento não foi observada postura de ovos nas carcaças expostas na mata de galeria. Este retardo na colonização de larvas de dípteros nestes ambientes também pode ter contribuído para prolongação dos estágios de decomposição (e.g. Voss et al. 2008), pois essas larvas consomem a maior parte da biomassa da carcaça (Payne 1965; Simmons et al. 2010).

Composição e sucessão de dípteros necrófagos nas carcaças

Neste estudo demonstramos que carcaças pequenas podem sustentar elevada riqueza de espécies de dípteros necrófagos pertencentes às famílias em estudo quando comparada a outros trabalhos com carcaças pequenas (Carvalho e Linhares 2001; Faria et al. 2013; Ledo et al. 2012). Além disso, observamos à presença de espécies de ambas as famílias que são de interesse forense no Brasil (Barros et al. 2008; Oliveira Costa 2008). A maior frequência da espécie C. albiceps observada nas duas fitofisionomias também foi observada em outros trabalhos (Carvalho e Linhares 2001; Biavati et al. 2010; Rosa et al. 2011). Estas informações se tornam relevantes visto que esta espécie compete com califorídeos nativos tais como C. macellaria e L. eximia, sendo necessária a realização de trabalhos posteriores para verificar o impacto da introdução da espécie C. albiceps e a consequente influência nas espécies nativas.

Diferenças na composição de insetos entre as fitofisionomias podem ser atribuídas às variações nas condições ambientais particulares de cada local (temperatura 
e umidade) que fornecem condições propícias para determinadas espécies (e.g. Smith, 1986; Mann et al. 1990; Sharanowski et al. 2008; Pechal et al. 2014). Por outro lado, a ocorrência de representantes da família Sarcophagidae ( $P$. pexata e $P$. trivittata) somente na fitofisionomia de cerrado sensu stricto está de acordo com outros trabalhos que também observaram a preferência de espécies desta família por ambientes mais abertos quando comparado a locais de mata fechada (Souza 2008). Igualmente, a ocorrência das espécies $M$. bicolor e $H$. semidiaphana somente na fitofisionomia de mata de galeria podem indicar a preferência destas por ambientes mais florestados (e.g. Gadelha et al. 2009; Ururahy-Rodrigues et al. 2013).

As fitofisionomias apresentaram sequência semelhante de espécies de dípteros ao longo do processo de decomposição. Com isso, a partir das mudanças nas condições físicas da carcaça cada estágio de decomposição pode apresentar características que tornem-se atrativo para um grupo diferente de insetos (Bornemissza 1957; Carvalho e Linhares 2001). As famílias de dípteros Calliphoridae e Sarcophagidae são conhecidas por serem colonizadores iniciais de carcaças (e.g. Bharti e Singh 2003; Voss et al. 2008, 2009; Biavati et al. 2010) e responsáveis pela redução da maior parte da biomassa destes recursos (Bharty e Singh 2003). No entanto, alguns autores sugerem que Sarcophagidae pode ser a principal família de dípteros associada à redução da biomassa de pequenas carcaças no Cerrado (Ledo et al. 2012), além de ser considerada pioneira na colonização de carcaças quando comparada aos califorídeos (Barros et al. 2008). Isso se deve à estratégia de desenvolvimento destes dípteros que são ovovivíparas, enquanto a maioria das espécies de Calliphoridae é ovípara (Barros et al. 2008; Ledo et al. 2012). Estas informações estão de acordo com este estudo, pois registramos o desenvolvimento dos imaturos de todas as espécies coletadas da família Sarcophagidae, enquanto para a família Calliphoridae observamos apenas as espécies $L$. eximia, $C$. albiceps, $C$. 
megacephala e $H$. segmentaria utilizando as carcaças como recurso para o desenvolvimento dos seus imaturos. Contudo, apesar deste menor número de espécies da família Calliphoridae se desenvolvendo no recurso estes foram muito representativos, ressaltando a grande importância destas famílias de dípteros (Calliphoridae e Sarcophagidae) na decomposição de carcaças de pequena biomassa.

A colonização inicial das carcaças pelas espécies $L$. eximia e P. intermutans também foi observada por outros trabalhos (Moretti et al. 2008; Ledo et al. 2012). Isto pode ser decorrente de especializações destes dípteros em colonizar recursos de menor biomassa, a fim de evitar a competição com outras espécies de dípteros (Moretti et al. 2008; Ledo et al. 2012). Além disso, observamos neste trabalho que L. eximia apresenta elevado potencial para ser utilizado como indicador do estágio fresco na mata de galeria no Cerrado. A ocorrência de espécies consideradas de natureza assinantrópica ( $M$. bicolor) pode ser considerada como potenciais indicadores de ambientes florestais preservados (Gadelha et al. 2009). Entretanto, neste trabalho a distribuição da comunidade de dípteros demonstra também índices de sinantropia (e.g. presença da espécie C. albiceps). Assim, estudos futuros que observarem mudanças na composição de espécies de dípteros necrófagos em carcaças de pequena biomassa podem indicar sinais de antropização do ambiente.

Agentes secundários de sucessão tais como $C$. albiceps são conhecidos por ocorrer em eventos de colonização mais tardios devido ao hábito predatório das larvas (Biavati et al. 2010), como o encontrado no presente estudo. Além disso, a obtenção desta espécie como indicadora do estágio seco no cerrado sensu stricto está de acordo com outros trabalhos que também observaram um grande número de indivíduos no final do processo de decomposição (Barbosa et al. 2010). A ocorrência de espécies do gênero Hemilucilia em fases intermediárias de decomposição também esta de acordo com 
trabalhos realizados no cerrado (e.g. Biavati et al. 2010). Entretanto, outros estudos indicam que a ocorrência deste gênero pode ser variável entre os estágios de decomposição (Moura et al. 1997; Ururahy-Rodrigues et al. 2013). Além disso, as espécies coletadas neste trabalho (e.g. H. semidiaphana e H. segmentaria) são relatadas na literatura como espécies comuns de ambientes florestados (Moura et al. 1997; Ururahy-Rodrigues et al. 2013), porém neste estudo $H$. segmentaria foi encontrada no cerrado sensu stricto, corroborando com o encontrado por Biavati e colaboradores (2010) no cerrado. Com isso, estes resultados podem sugerir que para o Cerrado esta espécie apresenta comportamento diferenciado de outras regiões do Brasil, tais como Manaus (Ururahy-Rodrigues et al. 2013) e Curitiba (Moura et al. 1997). Todavia não necessariamente todas as espécies que visitam as carcaças à utilizam como fonte de recursos para o desenvolvimento de seus imaturos, como por exemplo, C. idioidea (e.g. Ururahy-Rodrigues et al. 2013). Porém estas espécies podem apresentar preferência por determinados estágios de decomposição e assim contribuir como indicadores de tais fases.

As espécies pertencentes à família Sarcophagidae registradas apresentaram maior número de espécies associados aos estágios intermediários de decomposição, como o observado por Barros e colaboradores (2008) em carcaças expostas em uma área do Cerrado. Todavia, estes resultados se opõem a outros trabalhos que sugerem a associação de representantes desta família com estágios mais avançados de decomposição (Carvalho e Linhares 2001). Entre as espécies de Sarcophagidae registradas, $O$. fluminensis, $O$. thornax e $P$. intermutans já foram coletadas em cadáveres humanos no Brasil (Barros et al. 2008). Por outro lado, a ocorrência de dípteros (C. albiceps, C. megacephala e $C$. idioidea) no estágio final de decomposição nos ambientes se opõe a outros estudos que sugerem a preferência destes insetos pelos 
estágios iniciais de decomposição (Carvalho e Linhares 2001). Contudo, sobre uma perspectiva geral destes relatos observamos que a ocorrência das espécies de dípteros em relação aos estágios de decomposição apresenta grande variação na distribuição temporal destas espécies entre regiões.

A partir da análise de agrupamento observamos que a composição de espécies ao longo do processo de decomposição sugere que o processo de sucessão de dípteros necrófagos nas carcaças apresenta-se como um contínuo de mudanças graduais (Schoenly e Reid 1987; Boulton e Lake 1988; Moura et al. 2005 ). Isto se deve, pois os estágios de decomposição não apresentaram uma composição de espécies distinta para cada fase de decomposição. Moura et al. (2005) e colaboradores também sugerem que por não haver uma separação temporal entre os imaturos que colonizam as carcaças o processo de sucessão também indica um padrão contínuo e não discreto. Por outro lado, a não formação de grupos distintos da fauna de dípteros necrófaga para cada fase de decomposição demonstra que as espécies que visitam as carcaças não seguem a descrição dos estágios de decomposição propostos na literatura. Assim, a descrição dos estágios de decomposição utilizados por entomologistas podem ser subjetivos para explicar os padrões de sucessão da fauna que ocorre em carcaças (Schoenly e Reid 1987).

De modo geral, este estudo demonstrou que carcaças pequenas podem sustentar uma comunidade de dípteros necrófagos diversa, apesar da menor biomassa disponível para colonização e consumo. Além disso, o padrão de sucessão contínuo foi semelhante a outros trabalhos realizados com carcaças menores (Schoenly e Reid 1987; Boulton e Lake 1988; Moura et al. 2005) indicando que este tipo de recurso pode servir como sistema modelo para experimentos de sucessão. Outros fatores que podem contribuir para a utilização de pequenas carcaças nestes estudos é a (i) diminuição do tempo de 
experimento devido às maiores taxas de decomposição das carcaças (ii) facilidade na replicação do experimento e (iii) elevada disponibilidade das carcaças.

\section{Conclusões}

A duração do processo de decomposição e a duração dos estágios de decomposição, fresco e decomposição ativa, foi menor no cerrado sensu stricto do que na mata de galeria. Estas diferenças foram principalmente atribuídas às variações nas condições microclimáticas (e.g. temperatura e umidade) de cada local, decorrentes da estrutura da vegetação.

A composição de dípteros necrófagos difere entre as fitofisionomias de cerrado sensu stricto e mata de galeria. Além disso, observamos a ocorrência de espécies $(H$. semidiaphana e $M$. bicolor) somente na fitofisionomia de mata de galeria e do cerrado sensu stricto ( $P$. trivittata, $P$. pexata).

Há espécies de dípteros necrófagos potencialmente indicadores dos estágios de decomposição fresco na mata de galeria e de decomposição avançada e seco no cerrado sensu stricto. Dentre estas espécies, destaca-se L. eximia que apresenta elevado potencial para ser utilizada como indicadora do estágio fresco na mata de galeria.

Há sucessão de dípteros necrófagos nas duas fitofisionomias. O padrão de sucessão é caracterizado pela presença das espécies $L$. eximia e $P$. intermutans como colonizadores primários, $C$. albiceps, $C$. megacephala, $O$. thornax, $O$. fluminensis e $P$. collusor são colonizadores secundários. Colonizadores dos últimos estágios observamse as espécies $C$. idioidea, C. albiceps, C. megacephala e P. intermutans.

O processo de sucessão de dípteros neste estudo apresenta-se como um contínuo de mudanças graduais, visto que os estágios de decomposição não apresentam uma composição de espécies distinta para cada fase. 


\section{Considerações finais}

A sucessão em recursos efêmeros pode ser utilizada para descrever o processo de substituição da fauna necrófaga em escala temporal. Desta forma, este processo pode ser abordado como discreto ou contínuo. O nosso trabalho foi de ordem exploratória e demonstrou resultados promissores que, apesar de suas limitações abriu caminhos para estudos futuros dessa natureza em carcaças pequenas. Além disso, muitos ecossistemas naturais, tais como o bioma Cerrado, apresentam características naturais (e.g. estações definidas, ambientes com condições climáticas contrastantes) que devem ser alvo de estudos posteriores a fim de contribuir com dados de referência para a área geográfica em estudo.

Desta forma, este estudo, como uma pesquisa exploratória, contribui com dados relevantes sobre o processo de sucessão. Entretanto, estudos posteriores, devem apresentar um delineamento experimental que contemple um período de tempo mais prolongado, além de repetições anuais. Além disso, o experimento não necessariamente precisa ser exaustivo, visto que neste trabalho observamos o processo de sucessão com um delineamento experimental relativamente pequeno. Assim, experimentos que considerem tais sugestões podem fornecer dados mais robustos sobre o processo de sucessão da fauna necrófaga. 


\section{Referências bibliográficas}

Aballay, F.H., A.F. Murua, J.C. Acosta \& N.D. Centeno, 2012. Succession of carrion fauna in the arid region of San Juan province, Argentina and its forensic relevance. Neotropical Entomology, 41: 27-31.

Almeida, L.M. \& K.M. Mise, 2009. Diagnosis and key of the main families and species of South American Coleoptera of forensic importance. Revista Brasileira de Entomologia, 53: 227-244.

Anderson, G.S., V.J. Cervenka, W. Haglund \& M. Sorg, 2002. Insects associated with the body: their use and analyses. Advances in Forensic Taphonomy: Method, Theory, and Archaeological Perspectives, 177-200.

Archer, M.S., 2004. Rainfall and temperature effects on the decomposition rate of exposed neonatal remains. Science \& Justice, 44: 35-41.

Barbosa, R.R., C.A. Mello Patiu, A. Ururahy-Rodrigues, C.G. Barbosa \& M.M.C. Queiroz, 2010. Temporal distribuition of ten calyptrate dipteran species of médicolegal importance in Rio de Janeiro, Brazil. Memórias do Instituto Oswaldo Cruz, 105: 191-198.

Barros, R.M., C.A. Mello Patiu \& J.R. Pujol-Luz, 2008. Sarcophagidae (Insecta, Diptera) associados à decomposição de carcaças de Sus scrofa Linnaeus (Suidae) em área de Cerrado do Distrito Federal, Brasil. Revista Brasileira de Entomologia, 52: 606-609.

Bharti, M. \& D. Singh, 2003. Insect faunal succession on decaying rabbit carcasses in Punjab, India. Journal of Forensic Sciences, 48: 1133-43. 
Biavati, G.M., F.H. Assis Santana \& J.R. Pujol-Luz, 2010. A checklist of Calliphoridae blowflies (Insecta, Diptera) associated with a pig carrion in Central Brazil. Journal of Forensic Sciences, 55: 1603-1606.

Bornemissza, G.F., 1957. An analysis of Arthropod succession in Carrion and the effect of its decomposiion on the soil fauna. Australian Journal of Zoology, 5: 1-12.

Boulton, A.J. \& P.S. Lake, 1988. Dynamics of heterotrophic succession in carrion arthropod assemblages. Oecologia, 76: 477-480.

Buenaventura, E. \& T. Pape, 2013. Revision of the New World genus Peckia RobineauDesvoidy (Diptera: Sarcophagidae). Zootaxa, 3622: 001-087.

Campobasso, C.P., G. Di Vella \& F. Introna, 2001. Factors affecting decomposition and Diptera colonization. Forensic Science International, 120: 18-27.

Carvalho, L.M. \& A.X. Linhares, 2001. Seasonality of insect succession and pig carcass decomposition in a natural forest area in southeastern Brazil. Journal of Forensic Sciences, 46: 604-608.

Carvalho, L.M. \& C.A. Mello-Patiu, 2008. Key to the adults of the most common forensic species of Diptera in South America. Revista Brasileira de Entomologia, 52: 390-406.

Catts, E. \& M.L. Goff, 1992. Forensic entomology in criminal investigations. Annual Review of Entomology, 37: 253-272.

Dufrêne, M. \& P. Legendre, 1997. Species assemblages and indicator species: the need for a flexible asymmetrical approach. Ecological Monographs, 67: 345-366.

Eberhardt, T.L. \& D.A. Elliot, 2008. A preliminary investigation of insect colonisation and succession on remains in New Zealand. Forensic Science International, 176: 217-223.

Eiten, G., 1972. The cerrado vegetation of Brazil. The Botanical Review, 38: 201-341. 
Estrada, D.A., M.D. Grella, P.J. Thyssen \& A.X. Linhares, 2009. Taxa de desenvolvimento de Chrysomya albiceps (Wiedemann) (Diptera: Calliphoridae) em dieta artificial acrescida de tecido animal para uso forense. Neotropical Entomology, 38: 203-207.

Faria, L.S., M.L. Paseto, F.T. Franco, V.C. Perdigão, G. Capel \& J. Mendes, 2013. Insects breeding in pig carrion in two environments of a rural area of the state of Minas Gerais, Brazil. Neotropical Entomology, 42: 216-222.

Favier, C.F., E.E. Vaughan, W.M. De Vos \& A.D.L. Akkerrnans, 2002. Molecular monitoring of succession of bacterial communities in human neonates. Applied and Environmental Microbiology, 68: 219-226.

Gadelha, B.Q., A.C.P. Ferraz, V. Magalhães \& A. Coelho, 2009. A importância dos mesembrinelíneos (Diptera: Calliphoridae) e seu potencial como indicadores de preservação ambiental. Oecologia Brasiliensis, 13: 660-664.

Grassberger, M. \& C. Frank, 2004. Initial study of arthropod succession on pig carrion in a central European urban habitat. Journal of Medical Entomology, 41: 511-523.

Instituto Brasileiro do Meio Ambiente e dos Recursos Naturais Renonáveis, 2001. Ecossistemas Brasileiros. Brasília, Edições Ibama, 49p.

Kosmann, C., R.D. Mello, E.S. Harterreiten-Souza \& J.R. Pujol-Luz, 2013. A list of current valid blow fly names (Diptera: Calliphoridae) in the Americas South of Mexico with key to the Brazilian species. EntomoBrasilis, 6: 74-85.

Lacerda, M.P.C., I.O. Barbosa, P.M. Campos, R.A. Papa, 2007. Utilização de sensoriamento remoto para o estabelecimento de relações entre vegetação nativa e classes de solos em mapeamento pedológico, Distrito Federal. Simpósio Brasileiro de Sensoriamento Remoto, 13 (SBSR), 3991-3996. 
Ledo, R.M.D., R.M. Barros \& J.R. Pujol-Luz, 2012. Sarcophagidae and Calliphoridae related to Rhinella schneideri (Anura, Bufonidae), Bothrops moojeni (Reptilia, Serpentes) and Mabuya frenata (Reptilia, Lacertilia) carcasses in Brasília, Brazil. Revista Brasileira de Entomologia, 56: 377-380.

Legendre, P. \& L. Legendre, 2012. Numerical Ecology. Third English edn. Elsevier, Netherlands.

Mann, R.W., W.M. Bass \& L. Meadows, 1990. Time since death and decomposition of the human body: variables and observations in case and experimental field studies. Journal of Forensic Sciences, 35: 103-111.

Matuszewski, S., D. Bajerlein, S. Konwerski \& K. Szpila, 2008. An initial study of insect succession and carrion decomposition in various forest habitats of Central Europe. Forensic Science International, 180: 61-69.

Matuszewski, S., D. Bajerlein, S. Konwerski \& K. Szpila, 2010. Insect succession and carrion decomposition in selected forests of Central Europe. Part 2: Composition and residency patterns of carrion fauna. Forensic Science International, 195: 4251.

Matuszewski, S., D. Bajerlein, S. Konwerski \& K. Szpila, 2011. Insect succession and carrion decomposition in selected forests of Central Europe. Part 3: Succession of carrion fauna. Forensic Science International, 207: 150-163.

Matuszewski, S., S. Konwerski, K. Frątczak \& M. Szafałowicz, 2014. Effect of body mass and clothing on decomposition of pig carcasses. International Journal of Legal Medicine, 128: 1039-1048.

McCune, B. \& M.J. Mefford, 2011. PC-ORD. Multivariate Analysis of Ecological Data. Version 6. MjM Software, Gleneden Beach, Oregon, U.S.A. 
Miranda, J.C., 2009. Sucessão ecológica: conceitos, modelos e perspectivas. SaBiosRevista de Saúde e Biologia, 4: 31-37.

Monteiro-Filho, E.L.A. \& J.L. Penereiro, 1987. Estudo de decomposição e sucessão sobre uma carcaça animal numa área do Estado de São Paulo, Brasil. Revista Brasileira de Biologia, 47: 289-295.

Moretti, T.D.C., O.B. Ribeiro, P.J. Thyssen \& D.R. Solis, 2008. Insects on decomposing carcasses of small rodents in a secondary forest in Southeastern Brazil. European Journal of Entomology, 105: 691-696.

Moura, M.O., C.J.B. Carvalho \& E.L.A. Monteiro-Filho, 1997. A preliminary analysis of insects of medico-legal importance in Curitiba, State of Paraná. Memórias do Instituto Oswaldo Cruz, 92: 269-274.

Moura, M.O., E.L.D.A. Monteiro-Filho \& C.J.B.D. Carvalho, 2005. Heterotrophic succession in carrion arthropod assemblages. Brazilian Archives of Biology and Technology, 48: 477-486.

Oksanen, J., F.G. Blanchet, R. Kindt, P. Legendre, P.R. Minchin, R.B. O'Hara, G.L. Simpson, P. Solymos, M. Henry, H. Stevens \& H. Wagner, 2013. Vegan: Community Ecology Package. R package.

Oliveira-Costa, J., 2008. Entomologia Forense: Quando insetos são vestígios. Tratado de perícias criminalísticas. $2^{\text {a }}$ ed. Editora Millennium, Campinas, SP, 420p.

Oliveira-Costa, J. \& C.A.D. Mello-Patiu, 2004. Application of forensic entomology to estimate of the postmortem interval (PMI) in homicide investigations by the Rio de Janeiro Police Department in Brazil. Anil Aggrawal's Internet. Journal of Forensic Medicine and Toxicology, 5: 40-44.

Pape, T., 1996. Catalogue of the Sarcophagidae of the world (Insecta: Diptera). Memoirs of Entomology International, 8: 1-558. 
Payne, J.A., 1965. A Summer carrion study of the baby pig Sus scrofa Linnaeus. Ecology, 46: 592-602.

Payne, J.A., 1972. Insects sucession and decomposition of pig carcasses in water. Journal of Entomological Science, 7: 153-162.

Pechal, J.L., M.E. Benbow, T.L. Crippen, A.M. Tarone \& J.K. Tomberlin, 2014. Delayed insect access alters carrion decomposition and necrophagous insect community assembly. Ecosphere, 5: 1-21.

Rafael, J.A., G.A.R. Melo, C.J.B. Carvalho, S.A. Casari \& R. Constatntino, 2012. Insetos do Brasil: Diversidade e Taxonomia. Editora Holos, ed. 1, 810p.

R Core Team, 2013. R: A language and environment for statistical computing. $R$ Foundation for Statistical Computing Vienna, Austria.

Ribeiro, J.F. \& B.M.T. Walter, 2008. As principais fitofisionomias do bioma Cerrado. Cerrado: ecologia e flora, 2: 151-212.

Rognes, K., 1997. The Calliphoridae (blowflies)(Diptera: Oestroidea) are not a monophyletic group. Cladistics, 13: 27-66.

Rosa, T.A., M. Babata, C.M. Souza, D.D. Sousa, C.A. Mello-Patiu \& J. Mendes, 2009. Dípteros de interesse forense em dois perfis de vegetação de cerrado em Uberlândia, MG. Neotropical Entomology, 38: 859-866.

Rosa, T.A., M.L. Babata, C.M.D. Souza, D.D. Sousa, C.A.D. Mello-Patiu, F.Z. Vaz-deMello \& J. Mendes, 2011. Arthropods associated with pig carrion in two vegetation profiles of Cerrado in the State of Minas Gerais, Brazil. Revista Brasileira de Entomologia, 55: 424-434.

Schoenly, K., M.L. Goff, J.D. Wells \& W.D. Lord, 1996. Quantifying statistical uncertainty in succession-based entomological estimates of the postmortem 
interval in death scene investigations: a simulation study. American Entomologist, 42: 106-112.

Schoenly, K. \& W. Reid, 1987. Dynamics of heterotrophic succession in carrion arthropod assemblages: discrete seres or a continuum of change? Oecologia, 73: 192-202.

Scudder, G.G.E. \& R.A. Cannings, 2006. The Diptera families of British Columbia. 7277.

Sharanowski, B.J., E.G. Walker \& G.S. Anderson, 2008. Insect succession and decomposition patterns on shaded and sunlit carrion in Saskatchewan in three different seasons. Forensic Science International, 179: 219-240.

Simmons, T., R.E. Adlam \& C. Moffatt, 2010. Debugging decomposition datacomparative taphonomic studies and the influence of insects and carcass size on decomposition rate. Journal of forensic sciences, 55: 8-13.

Smith, K.G.V., 1986. A Manual of Forensic Entomology. Oxford: British Museum (Natural History) and Cornell University Press, London. 205p.

Sousa, J.R.P., 2008. A fauna de califorídeos e sarcofagídeos (Insecta, Diptera) das matas e clareiras com diferentes coberturas vegetais da base de extração petrolífera, Bacia do Rio Urucu, Coari, Amazonas. 116 f. Dissertação (Mestrado) - Universidade Federal do Pará, Museu Paraense Emílio Goeldi, Belém, 2008. Programa de Pós-Graduação em Zoologia.

Sutherland, A., J. Myburgh, M. Steyn \& P.J. Becker, 2013. The effect of body size on the rate of decomposition in a temperate region of South Africa. Forensic Science International, 231: 257-262. 
Tantawi, T.I., E.M. El-Kady, B. Greenberg \& H.A. El-Ghaffar, 1996. Arthropod succession on exposed rabbit carrion in Alexandria, Egypt. Journal of Medical Entomology, 33: 566-580.

Ururahy-Rodrigues, A., J.A. Rafael \& J.R. Pujol-Luz, 2013. Temporal distribuition of bowflies of forensic importance (Diptera: Calliphoridae), in man-size domestic pigs carcasses, in the Forest Reserve Adolpho Ducke, Manaus, Amazonas, Brazil. EntomoBrasilis, 6: 09-22.

Voss, S.C., D.F. Cook \& I.R. Dadour, 2011. Decomposition and insect succession of clothed and unclothed carcasses in Western Australia. Forensic Science International, 211: 67-75.

Voss, S.C., S.L. Forbes \& I.R. Dadour, 2008. Decomposition and insect succession on cadavers inside a vehicle environment. Forensic Science, Medicine, and Pathology, 4: 22-32.

Voss, S.C., H. Spafford \& I.R. Dadour, 2009. Annual and seasonal patterns of insect succession on decomposing remains at two locations in Western Australia. Forensic Science International, 193: 26-36. 